\title{
1 Mapping diversification metrics in macroecological studies: Prospects and challenges
}

3 Julián A. Velasco ${ }^{1^{*}}$ \& Jesús N. Pinto-Ledezma ${ }^{2,3}$

$4 \quad{ }^{1}$ Museo de Zoología Alfonso L. Herrera, Facultad de Ciencias, Universidad Nacional Autónoma de

5 México, Mexico City, Mexico.

$6{ }^{2}$ Department of Ecology, Evolution, and Behavior, University of Minnesota, 1479 Gortner Ave,

7 Saint Paul MN 55108, United States.

$8{ }^{3}$ Museo de Historia Natural Noel Kempff Mercado, Universidad Autónoma Gabriel René Moreno,

9 Av. Irala 565, C.C. 2489, Santa Cruz de la Sierra, Bolivia.

10

11 *Corresponding author: juvelas@gmail.com

12 ORCID: https://orcid.org/oooo-0002-2183-5758 


\section{Abstract}

17 The intersection of macroecology and macroevolution is one of the most active research areas

18 today. Macroecological studies are increasingly using phylogenetic diversification metrics to

19 explore the role of evolutionary processes in shaping present-day patterns of biodiversity.

20 Evolutionary explanations of species richness gradients are key for our understanding of how

21 diversity accumulated in a region. For instance, the present-day diversity in a region can be a

22 result of in situ diversification, extinction, or colonization from other regions, or a combination of

23 all of these processes. However, it is unknown whether these metrics capture well these

24 diversification and dispersal processes across geography. Some metrics (e.g., mean root distance

25 -MRD-; lineage diversification-rate -DR-; evolutionary distinctiveness -ED-) seem to provide very

26 similar geographical patterns regardless of how they were calculated (e.g., using branch lengths

27 or not). The lack of appropriate estimates of extinction and dispersal rates in phylogenetic trees

28 can limit our conclusions about how species richness gradients emerged. With a review of the

29 literature and complemented by an empirical comparison, we show that phylogenetic metrics by

30 itself are not capturing well the speciation, extinction and dispersal processes across the

31 geographical gradients. Furthermore, we show how new biogeographic methods can improve our

32 inference of past events and therefore our conclusions about the evolutionary mechanisms

33 driving regional species richness. Finally, we recommend that future studies include several

34 approaches (e.g., spatial diversification modelling, parametric biogeographic methods) to

35 disentangle the relative the role of speciation, extinction and dispersal in the generation and

36 maintenance of species richness gradients. 
bioRxiv preprint doi: https://doi.org/10.1101/261867; this version posted February 8,2018 . The copyright holder for this preprint (which was not certified by peer review) is the author/funder. All rights reserved. No reuse allowed without permission.

38 Keywords: Phylogeny, Geography, Spatial diversification, Macroevolution, Species

39 richness, Regional assemblages 
The causes of spatial variation of biodiversity are one of the most fundamental questions

42 in ecology, biogeography and macroecology (Brown 1995, 2014, Brown and Lomolino 1998,

43 Hawkins et al. 2012, Fine 2015, Jablonski et al. 2017). Current studies are integrating in a single

44 framework the ecological and evolutionary mechanisms driving regional species diversity

45 (McGaughran 2015, Pärtel et al. 2016, Cabral et al. 2017, Leidinger and Cabral 2017). However, only three macroevolutionary processes ultimately can modify the number of species in a region:

47 speciation, extinction and dispersal (Wiens 2011, Fine 2015, Jablonski et al. 2017) (Figure 1). These

48 processes can be modulated by species' traits varying within clades (Paper et al. 2016, 2017,

49 Jezkova and Wiens 2017, Moen and Wiens 2017), age of region (e.g., time-for-speciation effect;

50 Stephens \& Wiens, 2003), geographical area (Losos and Schluter 2000), or climatic conditions

51 (Condamine et al. 2013, Lewitus and Morlon 2017).

The integration of different disciplines such as molecular phylogenetics, palaeontology,

53 and historical biogeography have allow to infer a series of macroevolutionary processes across

54 geography (Diniz-Filho et al. 2013, Fritz et al. 2013). It is well-known that fossil information is key

55 to estimate with high confidence rates of speciation and extinction (Sepkoski 1998, Foote 2000,

56 Quental and Marshall 2010, Rabosky 2010b). New methods correcting for sampling bias are able

57 to generate improvements in the estimates of the speciation, extinction and net diversification

58 rates (Silvestro et al. 2014, 2016). However, the causal mechanisms that underlying the

59 geographical diversity gradients only can be established with greater confidence for a few

60 taxonomic groups with adequate fossil record, such as marine bivalves (Jablonski et al. 2006,

61 2017), mammals (Silvestro et al. 2014) or plants (Antonelli et al. 2015). 

approaches used to estimate speciation and extinction rates in palaeontology were adapted to study the macroevolutionary dynamics using phylogenetic information (Nee et al. 1994, Morlon et al. 2010, Stadler 2013). Molecular phylogenies are becoming essential to the study of diversification dynamics across temporal and spatial scales for extant taxa (Wiens and Donoghue

672004 , Rabosky and Lovette 2008, Stadler 2013, Morlon 2014, Schluter and Pennell 2017).

68 Therefore, it is possible to reconstruct past diversification process based on the branching events

69 of a phylogeny using a set of birth-death models (Nee et al. 1994, Nee 2006, Morlon et al. 2010,

70 Stadler 2013, Morlon 2014). These birth-death models allow infer either a homogeneous process

71 for an entire clade (Nee et al. 1994, Magallón and Sanderson 2001) or a heterogeneous process

72 varying in time or in specific subclades of a tree (Paper et al. 2006, Rabosky and Lovette 2008,

73 Alfaro et al. 2009). However, these birth-death models only account for temporal variation of the

74 macroevolutionary processes and how translate these processes to the geography is still a matter 75 of debate.

77 with the geographical ranges of species (Hawkins et al. 2007, Algar et al. 2009, Oian et al. 2014,

78 Pinto-Ledezma et al. 2017, Velasco et al. 2018). The first one uses a set of phylogenetic metrics as

79 a proxy to capture the geographical signature of lineage diversification dynamics (Diniz-Filho et

80 al., 2013; Fritz et al., 2013; Table 1; Figure 2). These metrics provide either an estimate of a per-

81 species rate of diversification (e.g., mean root distance -MRD-, residual phylogenetic diversity -

82 rPD-, mean diversification rate-MDR-), the phylogenetic structure of regional assemblages (e.g.,

83 phylogenetic species variability -PSV-) or the average age of co-occurring lineages in a given area

84 (e.g., mean age; see Table 1). Each metric is calculated for each species in the phylogeny;

85 therefore, we can associate the species' values to its corresponding geographical range and 
86 generate a map with average values for cells or regions. Although these phylogenetic metrics only

87 account for speciation events, macroecologists have used these maps as a proxy to test some

88 evolutionary-based hypothesis in macroecological research (Diniz-Filho et al., 2013; Fritz et al.,

892013 ; see Table 2 for a compendium of these hypotheses).

The second approach used by macroecologists consists in the explicit estimation of

91 diversification parameters across geography (Goldberg et al. 2005, 2011, Ramiadantsoa et al.

92 2017). For instance, the geographic state speciation and extinction model-GeoSSE (Goldberg et

93 al. 2011; Table 1) allows estimating speciation, extinction and dispersal parameters across two

94 regions. It is possible to disentangle the relative role of each one of these processes on the

95 generation and maintenance of the geographical diversity gradients (Rolland et al. 2014, Pulido-

96 Santacruz and Weir 2016, Pinto-Ledezma et al. 2017). In addition, a recently developed Bayesian

97 approach (BAMM; Rabosky 2014, Rabosky et al. 2014) allows to infer the balance of speciation

98 and extinction in the generation of these biodiversity gradients (Rabosky et al. 2015, Sánchez-

99 Ramírez et al. 2015, Morinière et al. 2016, Pinto-Ledezma et al. 2017). The BAMM approach allows

100 both the inference of macroevolutionary dynamics for an entire clade (i.e., a macroevolutionary

101 regime; Rabosky 2014) and also get estimates of per-species diversification rates (i.e., as a

102 phylogenetic metric; Rabosky 2016) that can be mapped in a geographical domain. Although all

103 these methods aim to obtain a geographical picture of the diversification processes, it remains

104 unexplored if they can effectively capture these dynamics across regions.

In this paper, we conducted a review on macroecological literature to evaluate how

106 evolutionary and biogeographic processes contribute to shape geographical species richness

107 gradients. We review only those papers that make explicit use of phylogenetic metrics and/or

108 explicit diversification approaches (Table 1). We divided our review in three main sections. In the 
109 first one, we discuss how studies use phylogenetic metric to test some evolutionary-based

110 hypotheses underlying geographical diversity gradients and we explore some limitations of these

111 metrics (see also Table 2). Also, we discuss to what extent these metrics are able to capture

112 macroevolutionary dynamics in a spatial explicit context. We illustrate these using three case

113 studies (Furnariides birds, Hylid frogs, and Anolis lizards; Figure 1) and explore how another

114 approaches (e.g., diversification modelling and biogeographical approaches) can complement our

115 inferences about diversification process across geography. In the second section, we discuss how

116 dispersal and extinction processes are limiting these diversification inferences and we propose

117 some research avenues to attempt to solve these problems. Using an explicit biogeographical

118 approach, we test the role of dispersal on the geographical species richness patterns of the three

119 case studies. Finally, in the third section, we call for the adoption of complementary approaches

120 (e.g., extensive simulations, parametric biogeographical methods) in macroecological research

121 with the aim to evaluate the relative role of speciation, extinction and dispersal process driving 122 geographical biodiversity gradients.

\section{LITERATURE REVIEW}

We conducted a literature search in Web of Science for studies that explicitly have

126 addressed questions on how speciation, extinction and dispersal have shaped geographical

127 species richness gradients. We selected those papers that used either phylogenetic metrics (e.g.,

128 mean root distance -MRD-, phylogenetic diversity -PD-, phylogenetic species variability -PSV-;

129 diversification rate -DR-; mean Ages; Table 1) or explicit macroevolutionary approaches (e.g.,

130 GeoSSE, BAMM; Goldberg et al., 2011; Rabosky 2014). We compiled a list of 44 papers (Table A1), 
131 but we are aware that this likely is not an exhaustive search. The majority of papers reviewed are

132 testing historical process shaping latitudinal diversity gradients (LDG) in various taxa.

Here, we discuss how phylogenetic metrics are used to test evolutionary hypotheses related to the generation and maintenance of geographical diversity. Several studies used the mean root distance -MRD- metric to evaluate whether regional assemblages are composed of

142 (Algar et al. 2009, Qian et al. 2015), it does provide the average number of nodes separating each 143 species in a given region from the root of the phylogeny (Kerr and Currie 1999). MRD therefore 144 provides information about the number of cladogenetic events (splits) that have occurred through 145 the history of co-occurring lineages in each region (Pinto-Ledezma et al. 2017, Velasco et al.

146 2018). Under this view, MRD should be interpreted as a metric of total diversification (Rabosky

147 2009), where high MRD values indicating regional assemblages dominated by extensive

148 cladogenesis and low MRD values indicating assemblages with few cladogenetic events. A main

149 concern with this metric concern with the fact that it does not provide any information about

150 what macroevolutionary dynamics have taken place in a region. For example, it is very hard to

151 establish whether MRD allows to distinguish between diversity-dependent (Rabosky 2009,

152 Rabosky and Hurlbert 2015) or time-dependent (Wiens 2011, Harmon and Harrison 2015)

153 processes dominating regional diversity. Although the distinction between these two dynamics, 
154 and its relationship with the origin and maintenance of regional diversity, is an intense topic in the 155 macroevolutionary literature (Rabosky 2009, 2013, Wiens 2011, Cornell 2013, Harmon and 156 Harrison 2015, Rabosky and Hurlbert 2015). However, more empirical and theoretical work is 157 necessary to establish what scenario plays a significant role in regional species richness assembly 158 (Rabosky 2012, Etienne et al. 2012, Valente et al. 2015, Graham et al. 2018). It might worth to establish whether local ecological process scaling up to regional scales or emergent effects (i.e., 160 the existence of a strong equilibrium process) governed the build-up of regional diversity (Cornell 161 2013, Harmon and Harrison 2015, Rabosky and Hurlbert 2015, Marshall and Quental 2016).

163 is directly proportional to the colonization time of its constituent clades (Stephens and Wiens 1642003 b; Table 2). However, many phylogenetic metrics used to test this hypothesis, did not 165 incorporate any age information (Fritz and Rahbek 2012, Qian et al. 2015). Qian et al. (2015) did 166 some additional predictions for the time effect hypothesis regarding the phylogenetic structure of 167 regional assemblages. We suggest that these predictions are not easily deduced from the original 168 statement of the time-for-speciation effect hypothesis (Stephens \& Wiens 2003). For instance, 169 Qian et al. (2015, p. 7) predicted that regions with low species richness (e.g., extra-tropical 170 regions) should be composed of more closely related species than regions with high species 171 richness (e.g., tropical regions). This assumes that regions with low species richness were 172 colonized recently and therefore these lineages had little time for speciation. However, it is also 173 plausible consider that high extinction occurred in these poor species richness regions by 174 marginal climatic niche conditions preventing adaptive diversification (Wellborn and Langerhans 175 2015). By contrast, regions with high species richness might also be assembled by multiple 176 dispersals from nearby regions becoming to be a macroevolutionary sink (Goldberg et al. 2005). In 177 this latter case, the species richness was not build-up by in situ speciation mainly but by continued 
178 dispersal through time. To evaluate which of these scenarios is more plausible it is necessary to 179 adopt an approach that explicitly infer the number of the dispersal and cladogenetic events across 180 areas (Roy and Goldberg 2007, Dupin et al. 2017). geographical diversity gradient for many groups (Kennedy et al. 2014, Pinto-Ledezma et al. 2017).

183 This hypothesis states (Table 2) that differences in net diversification rates between areas are the 184 main driver of differences in regional species richness between areas. Davies and Buckley (2011)

185 used the phylogenetic diversity controlled by species richness (i.e., residual PD -rPD-) to 186 distinguish areas with different evolutionary processes. These authors predicted that areas where 187 rapid speciation and low immigration events from other areas occurred, are dominated by large 188 adaptive radiations (e.g., large islands; Losos and Schluter 2000). By contrast, areas with slow 189 speciation and colonized by multiple lineages through time should have high values of residual 190 PD.

192 latitudinal diversity gradient is due to that the majority of lineages originated in the tropics and 193 then migrated to extratropical regions. Under this hypothesis, tropics harbour higher net 194 diversification rates (higher speciation and lower extinction) than extratropical regions and 195 dispersal rates are higher from the tropics to extratropical regions than the reverse (Jablonski et 196 al. 2006; Table 1). For instance, Rolland et al. (2014) used the GeoSSE model to test this 197 hypothesis in the generation of the latitudinal mammal diversity gradient. They found that net 198 diversification rates (i.e., the balance of speciation minus extinction) was higher in tropical than in 199 temperate regions and dispersal rates were higher from the tropics to temperate regions than the 200 reverse. Also, Pinto-Ledezma et al. (2017) used the GeoSSE model to test an analogue hypothesis 201 to OTT, as form of Out of the Forest hypothesis (OTF), using Furnariides birds as a clade model. 
202 Their favoured a model where open areas have higher speciation, extinction and dispersal rates

203 than forest habitats. All these results suggest that it is reasonable to use either phylogenetic

204 metrics or explicit diversification approaches (e.g., the GeoSSE model) to evaluate a set of

205 evolutionary-based hypotheses as a main driver of geographical diversity gradients. However, we

206 show here (see below) that these approaches fail to capture the evolutionary and biogeographic

207 processes at spatial scales.

\section{Are phylogenetic metrics capturing well the diversification process across geography?}

211 coming from the integration of molecular phylogenies and fossil record (Quental and Marshall

212 2010, Marshall 2017). From this integration of neontological and paleontological perspectives, it is

213 clear that both approaches are necessary to test evolutionary-based hypothesis in

214 macroecological research. Several hypotheses were proposed to explain geographical diversity

215 patterns, particularly the latitudinal diversity gradient-LDG- (see Table 2 for a summary and

216 compilation of the main hypotheses reported in the literature). Although the ideal approach is to

217 generate robust conclusions from multiple lines of evidence (e.g., fossil record, molecular

218 phylogenies, biogeographical inference) it is clear that this information is scarce for many

219 taxonomic groups. Many macroecological studies have adopted either phylogenetic metrics or

220 explicit diversification approaches (e.g., the GeoSSE model) to evaluate the relative contribution

221 of speciation, extinction and dispersal on the resulting geographical diversity gradients (Table S1).

222 Phylogenetic metrics can be easily visualized in a geographical context and several

223 inferences about ecological (e.g., dispersal) and evolutionary (e.g., speciation) process can be 
224 done. As these metrics provide a per-species level diversification metric for each species in a

225 phylogeny, it is possible to associate these values with the corresponding species' geographical

226 range and obtain a mean value for cells or regions in a given geographical domain (Table 1; Figure

227 2). By contrast, explicit diversification approaches (e.g., GeoSSE; BAMM; fitting models) provide a

228 per-lineage level diversification metric for a given clade or a regional assemblage (Rabosky 2016a).

229 However, in some cases, it is possible to generate a per-species level diversification metric with

230 these approaches. For instance, Pérez-Escobar et al. (2017) used the function GetTipsRates in

231 BAMMtools (Rabosky et al. 2014) to map speciation rates for Neotropical orchids.

234 geography. One the one hand, it is possible to estimate diversification rates for a given clade

235 using the number of species, its age and a birth-death models (Magallón and Sanderson 2001,

236 Nee 2006, Sánchez-Reyes et al. 2017). These model-fitting approaches allow to whether diversity-

237 or time-dependent diversification process has taken place in a regional assemblage (Etienne et al.

238 2012, Rabosky 2014, Valente et al. 2015). On the other hand, per-species diversification rate

239 metrics allow establishing the potential of each individual species to generate more species (Jetz

240 et al. 2012, Rabosky 2014, 2016a). However, these approaches imply at least a different process,

241 which left a different signature on the geography. Phylogenetic metrics captures a total

242 diversification process (Rabosky 2009), whereas lineage diversification approaches (e.g., BAMM)

243 can potentially provide information about an individual diversification process (Rabosky 2013). In

244 addition, still is not clear whether phylogenetic metrics can provide an accurate description of the

245 diversification dynamics across geography. 
248 phylogenetic metrics vary across geography and their relationship with species richness, we used

249 two empirical data sets from our own empirical work (furnariid birds and anole lizards; (Pinto-

250 Ledezma et al. 2017, Velasco et al. 2018) and a data set compiled from several sources (hylid

251 frogs; (Wiens et al. 2006, Algar et al. 2009, Pyron 2014a). We mapped across geography five

252 phylogenetic metrics (Table 1, Figure 2). We selected these three data sets because previous work

253 analysed how evolutionary-based hypotheses affected the present-day species richness gradient

254 (Wiens et al. 2006, Algar et al. 2009, Pinto-Ledezma et al. 2017, Velasco et al. 2018).

Figure 2 shows the geographical pattern of species richness and the five phylogenetic metrics

256 for Anolis lizards, hylid frogs and Furnariides birds. For all clades, there is a higher species

257 concentration near to the Ecuador. Higher species concentration for hylids and Furnariides can be

258 found in the Amazon and the Atlantic forest and for Anolis lizards in Central America and the

259 Caribe (Figure 2A-C; see also Algar et al. 2009, Pinto-Ledezma et al. 2017, and Velasco et al. 2018,

260 for a detailed description of the geographical species richness pattern for these clades,

261 respectively). In terms of the geographical pattern of each phylogenetic metric (Figure 2D-R), in

262 most of the cases cells with higher metric values are related to cells that contain high species

263 richness and vice versa (Figure 2D-R; Figure $A 1$ ). However, the degree and the direction of this

264 relationship changes according to the phylogenetic metric used. For example, MRD, a metric of

265 species derivedness, shows a negative correlation with species richness (Figure $2 \mathrm{~J}-\mathrm{L}_{i}$ Figure $\mathrm{A}_{1}$ ).

266 Importantly, the spatial relationships between species richness and phylogenetic metrics found in

267 our analysis could simply be the result of aggregated species-level attributes within cells or

268 assemblages (Hawkins et al. 2017). Hence, any conclusion derived from these relationships needs

269 to be considered carefully. In addition, there are different levels of correlation between

270 phylogenetic metrics (Figure A1). For example, MDR - MA present a high but negative correlation,

271 and rPD - PSV and MRD - MDR present a mid-high positive correlation (Figure A1). Although 
272 there are few studies comparing correlations between metrics (Vellend et al. 2010, Miller et al.

$2732017)$, to our knowledge, none previous study compares the similarity of these diversification

274 metrics (Table 1). However, some of these metrics sharing mathematical assumptions, which

275 increase the likelihood of correlation between them. For example, for ultrametric trees, metrics as

276 MDR could be approximated by considering the mean root distance (i.e. MRD metric) from the

277 tips to the root (Freckleton et al. 2008), so further studies exploring the mathematical relation

278 between metrics are needed.

In order to assess if the cells/assemblages on average do not represent a random sampling

280 from the species pool, we applied a simple permutation test to explore the non-randomness in

281 each of the phylogenetic metrics. We applied a null model where the presence-absence matrix

(i.e., PAM) was randomly shuffled 1000 times, but maintaining the frequency of species

283

occurrence and observed richness in the cells/assemblages (Gotelli 2000). This kind of null model

284 is standard in studies at the community/assemblage level that use phylogenetic information

285 (Cavender-Bares et al. 2004, 2006). Interestingly, none of the phylogenetic metrics deviates from

286 the null expectation for the three clades (Figure 3). Also, very few cells/assemblages present p-

287 values below the 0.05 threshold, thus indicating that the cells/assemblages present random

288 association among species (Figure 3). These results should be supported by repeating analyses

289 with more clades at different spatial extents, but again, we stress that any result obtained with

290 the use of phylogenetic metrics need to be interpreted carefully. 


\section{2}

293

\section{A brief comparison between phylogenetic metrics and explicit diversification and}

\section{biogeographic approaches}

We compared the phylogenetic metrics enunciated in Table 1, which have been the most used in macroecological research. We explored whether the geographical patterns of these phylogenetic metrics in three empirical examples coincide with the macroevolutionary dynamics inferred using explicit modelling diversification approaches. In particular, we implemented the GeoSSE model to estimate the three parameters (speciation, extinction, and dispersal) between two areas in each taxonomic group (Table 3 and 4 ). In addition, we used the BAMM approach to generate the per-species level diversification metric implemented in the software BAMM 2.5.0 (Rabosky 2014). In the following section, we discuss each metric and we compare them with the explicit diversification approaches.

\section{Residual Phylogenetic Diversity (rPD)}

In the case of furnariid birds, we show that forest areas tend to exhibit slightly higher values of rPD in contrast with open areas (Figure 4 ; see also Figure 2). According to Davies and Buckley's logic, these areas exhibit slow diversification and frequent dispersal from open areas.

Pinto-Ledezma et al. (2017) using GeoSSE and BAMM approaches indicated that open areas exhibit higher net diversification rates than open areas (Table 3). For hylid frogs, we found that tropical areas tend to exhibit higher rPD values than extratropical regions (Figure 5). However, by adopting an explicit diversification approach (GeoSSE and BAMM), we found that net diversification rates were similar in both regions (Table 3). In the case of Anolis lizards, the rPD values were higher in the continent than in the island areas (Figure 6). However, using GeoSSE 
314 and BAMM, we found that both rates were similar (Table 3). In a recent paper, Poe et al. (in press)

315 also found that macroevolutionary rates are similar between insular and mainland clades. All

316 these results suggest that rPD likely does not provide an accurate signature of the

317 macroevolutionary dynamic at spatial scales. In fact, it seems that rPD tends to overestimate

318 differences between regions when a stationary diversification process is occurring across

319 geography. A potential solution might be rethinking the way in which we visualize rPD across

320 geography in contrast with the original meaning by Davies \& Buckley (2011; see also Forest et al.

321 2007).

324 As we discussed, MRD captures a total diversification value portraying the number of

325 cladogenetic events co-occurring in a given region. In the case of furnariid birds, we found that

326 MRD values tend to be higher in open than forest areas (Figure 4). Accordingly, this metric

327 suggests that more cladogenetic events were accumulated in open areas (i.e., more total

328 diversification; Rabosky 2009). Therefore, this metric, for this bird clade, is consistent with results

329 from explicit diversification approaches (Table 3). For hylid frogs, it seems that there are no

330 differences in MRD values between extratropics and tropics areas (Figure 5). However, tropical

331 areas have some cells with very high values. Again, MRD provide an accurate description of the

332 total diversification pattern in this clade across the latitudinal gradient. In Anolis lizards, we found

333 that MDR values tend to be lower in islands in comparison with mainland areas (Figure 6). In this

334 case, MRD did not provide an accurate description of the evolutionary processes occurring

335 between the mainland and insular anole assemblages. However, there is also a high probability

336 that the high MRD values in the mainland are a direct reflect of an idiosyncratic evolutionary 
337 trajectory of each one of the two clades that radiated there (i.e., Draconura and Dactyloa clade;

338 see Poe et al. 2017, Velasco et al. 2018). These two clades seems to exhibit differential

339 diversification dynamics across geography (Velasco et al. 2018) but further research might be

340 necessary to evaluate these differences.

Phylogenetic species variability (PSV)

The PSV metric provides information about how related are the species in a given

344 regional assemblage. In hylid frogs, we found that tropical assemblages tend to be composed of

345 more related species than extratropical assemblages (Figure 5). Hylid assemblages in

346 extratropical areas are composed of multiple lineages that dispersed from tropical areas and then

347 diversified there. We found higher dispersal rates from tropical to temperate regions than vice

348 versa (Table 3 and 4 ). The same tendency is present in the case of furnariid birds where open

349 areas exhibit higher PSV values than forest areas (Figure 4) and dispersal rates were higher from

350 open to forest areas than the reverse (Table 3). By contrast, we did not find any evidence for

351 differences in PSV values between island and mainland Anolis assemblages (Figure 6). In addition,

352 the dispersal rates were very low between these two regions (Table 3; Poe et al. 2017). All these

353 results confirm that the PSV metric can provide some insights about how dispersal process have

354 shaped regional assemblages. We find evidence that low PSV values (i.e., phylogenetically over-

355 dispersed faunas) are influenced by multiple dispersals along its evolutionary history. 
Jetz et al. (2012) proposed MDR metric as a species-level speciation rate metric based in

359 the branch length along the path from the root of a tree to each individual species. In furnariid

360 birds, we noted that MDR was slightly higher in open versus forest areas and the same pattern is

361 present using the BAMM approach (Pinto-Ledezma et al. 2017; Figure 5i Table 3). For hylid frogs,

362 extratropical regions tend to exhibit higher values than tropical regions (Figure 5). MDR seems to

363 capture well the differences in macroevolutionary diversification for these taxa along the

364 latitudinal diversity gradient. A similar pattern is present when the BAMM approach is used (Table

365 3). We consider that both metrics (MDR vs per-species diversification rate from BAMM) leave the

366 same signature in the geography. In Anolis, we found that insular assemblages tend to exhibit

367 higher MDR values than continental assemblages (Figure 6), However, there is no difference in

368 the macroevolutionary dynamic between these two areas for the Anolis lizards clade (Poe et al. in

369 press, Velasco et al. 2018).

Mean ages (MA).

The average of ages of co-occurring lineages are used to test evolutionary hypothesis

373 about whether a region maintains older lineages than others (e.g., a museum) or a combination of

374 old and recent lineages (e.g., OTT hypothesis, Table 1). Although this metric does not provide any

375 inference of the ancestral area of the clade, it is possible to implement an explicit biogeographic

376 approach to test this (see below). For example, in hylid frogs, we found that extratropical areas

377 are composed of older lineages than tropical regions (Figure 5). The biogeographic parametric

378 approach infers this same area as ancestral for the entire lineage (Figure A2). In furnariid birds,

379 mean ages metric revealed that older lineages have accumulated more in forest than open areas

380 (Figure 4). In accordance, the ancestral area inferred with a parametric biogeographic method 
381 was the forest area (Figure $\mathrm{A}_{3}$ ). In the case of the anole lizards, insular settings tend to be

382 composed of older lineages than continents. However, the ancestral area for the entire anole

383 clade is the mainland, particularly South America (Poe et al. 2017). The mainland Anolis radiation

384 is composed of two clades, one clade that originated in South America (the Dactyloa clade; Poe et

385 al. 2017) and colonized Caribbean islands, and the other clade (the Norops clade; Poe et al. 2017)

386 that originated in the Caribbean islands and then colonized back the mainland in Middle America

387 and then dispersed to South America. Therefore, the biogeographical history of the Anolis

388 radiation is complex and involves multiple dispersals between islands and mainland areas (Poe et

389 al. 2017; Figure A4). In general, mean ages does not provide enough information about the

390 biogeographic origin and maintenance of a clade. This happens because multiple dispersals and in

391 situ cladogenesis might erase any simplistic pattern elucidated for this metric, as found in the

392 case of the Anolis lizards.

Dispersal is another key macroevolutionary process that ultimately determines the number of a

397 species in a region (Roy and Goldberg 2007, Eiserhardt et al. 2013, Rolland et al. 2014, Chazot et

398 al. 2016). However, few studies evaluated explicitly how the direction of dispersals between

399 region contributes to the generation of regional differences between areas (Chown and Gaston

4002000 , Goldberg et al. 2005, 2011, Jablonski et al. 2006). Roy and Goldberg (2007) showed with

401 simulations that dispersal asymmetry between areas had a strong impact in the regional species

402 richness and the average age of these lineages. Accordingly, phylogenetic metrics can be

403 sensitive to dispersal between areas because it is impossible to distinguish which lineages 
404 originated by in situ speciation or simply due to dispersal from nearby areas. Goldberg et al. (2011)

405 developed the GeoSSE model to evaluate how range evolution affected diversification rates in a

406 phylogenetic comparative approach. The GeoSSE model only considers three states (A: endemic

407 species to a region; $B$ : endemic species to another region; and AB for widespread species) and

408 makes a series of assumptions that can be problematic. The first assumption of the GeoSSE

409 model is that a time-dependent process dominates the diversification dynamic in each region

410 (Stephens and Wiens 2003, Wiens 2011). This assumption conflicts with a diversity-dependent

411 process assumption and this debate is far from being resolved (Cornell 2013, Harmon and

412 Harrison 2015, Rabosky and Hurlbert 2015). The second problematic assumption has to do with

413 the fact that the GeoSSE model consider dispersal rates as stable through time and lineages. In

414 other words, the dispersal ability and therefore the frequency of transitions between areas are

415 constant across the evolutionary history of a clade. There are many empirical evidence showing

416 that dispersal rates vary across time and space among lineages (McPeek and Holt 1992,

417 Sanmartín et al. 2008, Robledo-Arnuncio et al. 2014).

420 gradients (e.g., Rolland et al. 2014, Pyron 2014b, Staggemeier et al. 2015, Looney et al. 2016,

421 Morinière et al. 2016, Pulido-Santacruz and Weir 2016, Alves et al. 2017, Hutter et al. 2017, Pinto-

422 Ledezma et al. 2017). In a recent study, Rabosky and Goldberg (2015) found that state-dependent

423 diversification models tend to inflate excessively the false discovery rates (i.e., type I error rates).

424 In particular, Rabosky and Goldberg (2015) found that these models tend to find false associations

425 between trait shifts and shifts in macroevolutionary dynamics. Although the Rabosky and

426 Goldberg's study was not based on the GeoSSE model, it is clear that transitions between areas

427 (i.e., dispersal events) can be falsely associated with shifts in speciation and extinction rates 
428 across the phylogeny. Alves et al. (2017) also found that geographical uncertainties in the

429 assignment of species to a given area affect the parameter estimates (i.e., speciation, extinction

430 and dispersal rates) in the GeoSSE model. Same authors also evaluated how incorrect

431 assignments of bat species to tropical or extra-tropical regions can generate erroneous

432 conclusions about the relative role of speciation, extinction and dispersal on a latitudinal diversity

433 gradient. From these studies, it is clear that dispersal is a major issue that needs to be evaluated

434 explicitly in macroecological studies.

435 Pulido-Santacruz and Weir (2016) also used the GeoSSE model to disentangle the relative

436 effect of speciation, extinction and dispersal on the latitudinal bird diversity gradient. They found

437 that extinction was prevalent across all bird clades and therefore they suggest this as a main

438 driver of the geographical bird diversity gradient. Pyron (2014C), also using the GeoSSE model,

439 found that temperate diversity in reptiles is due to higher extinction in these areas. We consider

440 that extinction inferences from the GeoSSE model should be treated with caution. For the few

441 clades where fossil record is abundant (e.g., marine bivalves; Jablonski et al. 2006), studies point

442 out to conclude that extinction differences between regions should be treated with caution due to

443 the potential sampling bias (Jablonski et al. 2006, 2017). In addition, studies based on extensive

444 simulations found that extinction inferences based only in molecular phylogenies are not reliable

445 (Rabosky 2010a, 2016b, Quental and Marshall 2010), although extinction rates can be estimated

446 relatively well using medium to large phylogenies (Beaulieu \& O’Meara 2015).

447 In a recent review, Sanmartín and Meseguer (2016) proposed that it is possible to detect the

448 extinction signature in molecular phylogenies using extensive simulations and lineage-through-

449 time -LTT- plots (see also Antonelli and Sanmartín 2011). These authors also found that many

450 birth-death models leave a similar phylogenetic imprint, which make indistinguishable some 
451 scenarios. In addition, extinction events can affect substantially the ancestral range estimates,

452 and therefore dispersal and extinction parameters in several parametric biogeographic methods

453 (e.g., Dispersal-Vicariance-DIVA- and Dispersal-Extinction-Cladogenesis-DEC- models;

454 Ronquist 1997, Ree et al. 2005). Sanmartín and Meseguer (2016) finally proposed that the

455 adoption of a hierarchical Bayesian approach using continuous-time Markov Chain models will

456 allow a better estimation of extinction both in geography and in the phylogeny (Sanmartín et al.

$457 \quad 2008$, Sanmartin et al. 2010).

460 (Rabosky and Goldberg 2015). However, the FiSSE method does not allow the evaluation of the

461 contribution of dispersal on regional species richness. In any case, the best suitable framework to

462 estimate relative contributions of speciation, extinction and dispersal might be the GeoSSE

463 model (or parametric biogeographic models; e.g., Matzke 2014; see below), although it requires

464 the simulation of a series of null scenarios to evaluate the statistical power in each case (see Alves

465 et al. 2017, Pinto-Ledezma et al. 2017 for a few examples). For instance, Pinto-Ledezma et al.

466 (2017) developed a parametric bootstrapping approach simulating traits to evaluate whether

467 empirical inferences are different from the simulated. They simulated 100 datasets of neutral

468 characters along a set of empirical phylogenies and using this new information repeated the same

469 procedure with empirical data (see Appendix S1 in Pinto-Ledezma et al. 2017 for details of the

470 bootstrapping approach). This bootstrapping procedure assumes no direct effect of the

471 geographic character states on the parameter estimations (Feldman et al. 2016, Pinto-Ledezma

472 et al. 2017). 
Finally, it should be clear that more research would be necessary to establish how

474 extinction affect estimation parameters in state-dependent diversification approaches (e.g., the

475 GeoSSE model). For instance, the inclusion-exclusion of extinct species in simulated phylogenies

476 using birth-death models could substantially affect the geographical inferences of speciation,

477 extinction and dispersal parameters in the GeoSEE model. This kind of approach might provide

478 some lights on how to biased can be the parameter estimates with only molecular phylogenies

479 using the GeoSSE model or any other modeling approach.

Parametric biogeographical approaches in macroecological studies.

The use of parametric biogeographic approaches is an optimal solution to estimate

485 richness. Recently, Dupin et al. (2017) developed a biogeographical stochastic mapping to infer

486 the number of dispersals, and other biogeographical events, in the evolutionary history of

487 Solanaceae plants across the world. This approach allows the inference from multiple process

488 including sympatric speciation, allopatric speciation, founder-event speciation, range expansion

489 (i.e., dispersal without speciation) and local extinction (i.e., range contractions) based on a time-

490 calibrated phylogenetic tree and the occurrence of species in geographical regions (see also

491 Matzke 2014 for more detailed description of the method). These explicit biogeographical

492 approaches are promising in macroecological studies since they allow to test simultaneously a set

493 of evolutionary process during the diversification of a clade in a region (Velasco 2018). In addition,

494 with these new approaches it is possible to differentiate effectively between macroevolutionary

495 sources and sink areas (Goldberg et al. 2005, Castroviejo-Fisher et al. 2014, Poe et al. 2017). For 
496 instance, Poe et al. (2017) used a parametric biogeographical approach to estimate the number of 497 events among regions and distinguish those areas where many cladogenetic events occurred (i.e., 498 in situ speciation) and areas where almost all its diversity was build-up from extensive 499 colonization of other regions.

501 is promising to estimate more accurately the number of dispersal events between regions based

502 on a better estimation of the ancestral area for a clade. We evaluated how dispersal rates

503 between regions can affect inferences drawn only from phylogenetic metrics in our three data

504 sets. We implemented GeoSSE and BSM approaches for each data set (Table 3 and 4). For the

505 case of hylid frogs, we counted the inferred number of dispersal events between tropical and

506 extra-tropical regions in the Americas (Table 3; see also (Wiens et al. 2006, Algar et al. 2009). For

507 furnariid birds, we counted the number of dispersal events between open and forest areas (Table

508 3; see also Pinto-Ledezma et al. 2017). Finally, for anole lizards, we counted the number of

509 dispersal events between insular and mainland areas (Table 3; see also Algar and Losos 2011, Poe

510 et al. 2017, Velasco et al. 2018).

512 events from one region to another for each one of the three taxonomic groups examined (Table

513 3). The BSM approach allows us to disentangle which dispersals were only range expansions and

514 which dispersals generated a speciation event (i.e., a founder-event speciation; (Barton and

515 Charlesworth 1984, Templeton 2008). For furnariid birds, we found that range expansions were

516 three times higher from forest areas to open areas than the reverse and founder events were

517 twice higher from forest to open areas than the opposite (Table 3). This result suggests that

518 differences in species richness between forest and open areas are due by recurrent dispersal 
519 events along the furnariid diversification history (Pinto-Ledezma et al. 2017). Pinto-Ledezma et al.

520 (2017) found a similar result using the GeoSSE approach, but they conducted a parametric

521 simulation approach to evaluate whether there was a direct effect of the geographic location on

522 the parameter estimates. Their results show that the GeoSSE approach, in this case, had limited

523 power to detect a signature of geographic region on speciation, extinction and dispersal rates.

524 With the implementation of the BSM approach here, we corroborate Pinto-Ledezma et al.'s

525 findings with improved statistical power. In the case of hylid frogs and the transitions between

526 tropical and extra-tropical areas, we found that the BSM approach inferred more dispersal events

527 from tropical to extra-tropical regions (Table 3 and 4). However, the number of founder events

528 was relatively low in comparison with range expansions (Table 3). These results suggest that few

529 dispersal events have occurred across the diversification of hylid frogs and corroborate that the

530 species richness in each region largely originated by in situ speciation modulated by climatic

531 factors (Wiens et al. 2006, Algar et al. 2009). Finally, for Anolis lizards, we found that dispersal

532 events between insular and mainland regions were relatively low (Table 3 and 4 ). We did not find

533 evidence of any expansion range events from mainland to island or vice versa. This also

534 corroborates previous findings that evolutionary radiation of anole in insular and mainland

535 settings is due to extensive in situ diversification (Poe et al. in press, 2017, Algar and Losos 2011).

537 when we are interested in testing the role of anagenetic and cladogenetic events on the resulting

538 geographical species richness gradients. Although parametric biogeographic approaches are still

539 in their infancy (Sanmartín 2012, Matzke 2014, Dupin et al. 2017), these methods allow us to

540 evaluate macroevolutionary dynamics (i.e., speciation and extinction) in an explicit geographical

541 context. These methods are statistical powerful and make use of a series of explicit geographic

542 range evolution models (Velasco 2018). 
APPROACHES IN MACROECOLOGICAL STUDIES.

547 the last 20 years (Ronquist 1997, Ree et al. 2005, Landis et al. 2013, Matzke 2014, Dupin et al.

548 2017), the adoption of these methods to test evolutionary-based hypotheses underlying

549 geographical diversity gradient has been rare. For instance, few studies examined here tested

550 the effect of dispersal events in the generation of regional species richness assemblages. It should

551 clear that the current paradigm in biogeography makes a call for an evaluation of the relative

552 frequency of cladogenetic and anagenetic process during the biogeographical history of lineages.

553 The adoption of parametric approaches in future macroecological studies will contribute to an

554 improvement of the estimation of speciation, extinction and dispersal processes as drivers of the

555 geographical diversity gradients. In addition, we also think that it is necessary to establish which

556 macroevolutionary dynamics govern regional assemblages. Phylogenetic approaches based on

557 fitting diversification models help to test whether regional species richness is due to diversity

558 dependence (i.e., ecological limits), time dependence, or environmental factors (Rabosky and

559 Lovette 2008, Etienne et al. 2012, Etienne and Haegeman 2012, Condamine et al. 2013). We also

560 stress that the adoption of many approaches providing multiple lines of evidence will help to

561 disentangle the evolutionary and ecological causes of biodiversity gradients. Some recent studies

562 have pointed toward this strategy and have begun to provide evidence from many lines to

563 understand how evolutionary processes underlying species richness gradients works (Hutter et al.

564 2017, Pinto-Ledezma et al. 2017). 
566

567

568

569

570

571

572

573

574

575

576

\section{Conclusions and recommendations}

The resulting geographical pattern of several phylogenetic metrics did not provide any robust evidence of a spatially explicit diversification dynamic. As we have shown, these resulting geographical patterns did not differ from that generated by a simple null model. It is hard to untangle causal mechanisms (i.e., speciation, extinction, and dispersal) from only the geographical signature that these metrics attempt to capture. We recommend that phylogenetic metrics should be used only to visualize geographical patterns of total diversification (e.g., MRD, residual PD; MDR), phylogenetic structure (e.g., PSV), or mean ages of co-distributed species (e.g., MA) (Table 1). We suggest that conclusions about the role of evolutionary processes in the generation and maintenance of species richness gradients based only in these phylogenetic metrics should be avoided and additional approaches always should be used.

Some explicit diversification approaches (e.g., model fitting approaches; (Etienne et al. 2012, Rabosky 2014, Valente et al. 2015) are useful to establish the macroevolutionary dynamics operating at regional scales. Although some approaches (e.g, the GeoSSE model) allow us to evaluate the relative role of the ultimate process that modify the regional species diversity, its statistical power (e.g., high Type I errors) has been challenged by simulation and empirical studies. Furthermore, the extinction and dispersal estimates inferred by the GeoSSE model tend to be unbiased. Parametric biogeographic approaches are becoming a standard tool to evaluate how evolutionary processes can explain the geographical distribution of extant taxa. These approaches are promising and should be extensively used because allow us to estimate the relative frequency of cladogenetic and anagenetic process shaping the regional species richness. 
589 process have shaped regional species richness assemblages. As Jablonski et al. (2017) have

590 outlined, one of the main obstacles to generate an appropriate understanding of the causal

591 mechanisms underlying geographical diversity gradients has been that many studies have tested

592 a single hypothesis, either evolutionary or ecological, as an explanatory factor. We suggest that

593 ecological and evolutionary hypotheses should be tested simultaneously to explain the relative

594 contribution of each process to the regional diversity. As shown by our empirical comparison of

595 phylogenetic metrics, explicit diversification models, and historical biogeographic methods have

596 showed, it is necessary to obtain evidence of different approaches to guarantee sound

597 conclusions about the evolutionary causes of these biodiversity gradients.

\section{Acknowledgments}

600 We thank Josep Padullés for reviewing the English. JAV is supported by a Postdoctoral fellowship

601 from DGAPA program at Facultad de Ciencias of the UNAM. JAV thanks to Oscar Flores Villela for 602 providing a working space at Museo of Zoologia "Alfonso L. Herrera" and insightful discussions

603 about historical biogeography and evolutionary biology. JNPL is supported by a Postdoctoral

604 research fellowship from the Grand Challenge in Biology Postdoctoral Program, College of

605 Biological Sciences, University of Minnesota.

606

607 Literature cited

608 Alfaro, M. E. et al. 2009. Nine exceptional radiations plus high turnover explain species diversity in 609 jawed vertebrates. - Proc. Natl. Acad. Sci. U. S. A. 106: 13410-4.

610 Algar, A. C. and Losos, J. B. 2011. Evolutionary assembly of island faunas reverses the classic 
island - mainland richness difference in Anolis lizards.: 1125-1137.

612 Algar, A. C. et al. 2009. Evolutionary constraints on regional faunas: whom, but not how many. -

$613 \quad$ Ecol. Lett.: $57-65$.

614 Alves, D. M. C. C. et al. 2017. Geographical diversification and the effect of model and data

615 inadequacies: The bat diversity gradient as a case study. - Biol. J. Linn. Soc. 121: 894-906.

616 Antonelli, A. and Sanmartín, I. 2011. Mass extinction, gradual cooling, or rapid radiation?

617 Reconstructing the spatiotemporal evolution of the ancient angiosperm genus Hedyosmum

618 (Chloranthaceae) using empirical and simulated approaches. - Syst. Biol. 60: 596-615.

619 Antonelli, A. et al. 2015. An engine for global plant diversity: highest evolutionary turnover and

620 emigration in the American tropics. - Front. Genet. 6: 1-14.

621 Barton, N. H. and Charlesworth, B. 1984. Genetic Revolutions, Founder Effects, and Speciation. -

$622 \quad$ Annu. Rev. Ecol. Syst. 15: 133-164.

623 Baum, D. A. et al. 2005. The tree-thinking challenge. - Science (80-. ). 310: 979-980.

624 Brown, J. 1995. Macroecology. - University of Chicago Press.

625 Brown, J. H. 2014. Why are there so many species in the tropics? - J. Biogeogr. 41: 8-22.

626 Brown, J. H. and Lomolino, M. V. 1998. Biogeography. - Sinauer Associates, Inc.

627 Buckley, L. B. et al. 2010. Phylogeny, niche conservatism and the latitudinal diversity gradient in 628 mammals. - Proc. Biol. Sci. 277: 2131-8.

629 Cabral, J. S. et al. 2017. Mechanistic simulation models in macroecology and biogeography: state-

630 of-art and prospects. - Ecography (Cop.). 40: 1-14. 
631 Castroviejo-Fisher, S. et al. 2014. Neotropical diversification seen through glassfrogs (M Ebach,

$632 \quad$ Ed.). - J. Biogeogr. 41: 66-8o.

633 Cavender-Bares, J. et al. 2004. Phylogenetic Overdispersion in Floridian Oak Communities. - Am.

$634 \quad$ Nat. 163: 823-843.

635 Cavender-Bares, J. et al. 2006. Phylogenetic structure of floridian plant communities depends on

636 taxonomic and spatial scale. - Ecology 87: 109-122.

637 Chazot, N. et al. 2016. Into the Andes: multiple independent colonizations drive montane

638 diversity in the Neotropical clearwing butterflies Godyridina. - Mol. Ecol. 25: 5765-5784.

639 Chown, S. L. and Gaston, K. J. 2000. Areas cradles and museums: The latitudinal gradient in

640 species richness. - Trends Ecol. Evol. 15: 311-315.

641 Condamine, F. L. et al. 2013. Macroevolutionary perspectives to environmental change. - Ecol.

$642 \quad$ Lett. 16 Suppl 1: 72-85.

643 Cornell, H. V 2013. Is regional species diversity bounded or unbounded? - Biol. Rev. Camb. Philos.

644 Soc. $88:$ 140-65.

645 Crisp, M. D. and Cook, L. G. 2005. Do early branching lineages signify ancestral traits? - Trends

$646 \quad$ Ecol. Evol. 20: 122-128.

647 Davies, T. J. and Buckley, L. B. 2011. Phylogenetic diversity as a window into the evolutionary and

648 biogeographic histories of present-day richness gradients for mammals. - Philos. Trans. R.

649 Soc. Lond. B. Biol. Sci. 366: 2414-25.

650 Diniz-Filho, J. A. F. et al. 2013. Evolutionary macroecology. - Front. Biogeogr. 5: 1-11. 
651 Dupin, J. et al. 2017. Bayesian estimation of the global biogeographical history of the Solanaceae. - J. Biogeogr. 44: 887-899.

Eiserhardt, W. L. et al. 2013. Dispersal and niche evolution jointly shape the geographic turnover of phylogenetic clades across continents. - Sci. Rep. 3: 1164.

Etienne, R. S. and Haegeman, B. 2012. A Conceptual and Statistical Framework for Adaptive Radiations with a Key Role for Diversity Dependence. - Am. Nat. 180: E75-E89.

Etienne, R. S. et al. 2012. Diversity-dependence brings molecular phylogenies closer to agreement with the fossil record. - Proc. Biol. Sci. 279: 1300-9. and the tuatara. - Glob. Ecol. Biogeogr. 25: 187-197. Diversity. - Annu. Rev. Ecol. Evol. Syst. 46: 369-392.

Foote, M. 2000. Origination and extinction components of taxonomic diversity: general problems. - Paleobiology 26: 74-102.

668 Fritz, S. a. and Rahbek, C. 2012. Global patterns of amphibian phylogenetic diversity. - J. Biogeogr. 39: 1373-1382. 

509-16.

672 Goldberg, E. E. et al. 2005. Diversity, Endemism, and Age Distributions in Macroevolutionary 673 Sources and Sinks. - Am. Nat. 165: 623-633.

674 Goldberg, E. E. et al. 2011. Phylogenetic inference of reciprocal effects between geographic range 675 evolution and diversification. - Syst. Biol. 6o: 451-65.

676 Gotelli, N. J. 2000. Null Model Analysis of Species Co-Occurrence Patterns. - Ecology 81: 2606.

677 Graham, C. H. et al. 2018. Phylogenetic scale in ecology and evolution. - Glob. Ecol. Biogeogr. 27: $678 \quad 175-187$.

679 Harmon, L. J. and Harrison, S. 2015. Species Diversity Is Dynamic and Unbounded at Local and 680 Continental Scales. - Am. Nat. 185: 584-593.

681

Hawkins, B. a et al. 2007. Climate, niche conservatism, and the global bird diversity gradient. -

682 Am. Nat. 170 Suppl: S16-27.

683

Hawkins, B. a. et al. 2012. Different evolutionary histories underlie congruent species richness gradients of birds and mammals. - J. Biogeogr. 39: 825-841.

Hawkins, B. A. et al. 2017. Structural bias in aggregated species-level variables driven by repeated species co-occurrences: a pervasive problem in community and assemblage data. - J. Biogeogr. 44: 1199-1211.

Helmus, M. R. et al. 2007. Phylogenetic measures of biodiversity. - Am. Nat. 169: E68-83. 
691 Jablonski, D. et al. 2006. Out of the tropics: Evolutionary dynamics of the latitudinal diversity

692 gradient. - Science (80-. ). 314: 102-106.

693 Jablonski, D. et al. 2017. Shaping the Latitudinal Diversity Gradient: New Perspectives from a

694 Synthesis of Paleobiology and Biogeography. - Am. Nat. 189: 1-12.

695 Jetz, W. et al. 2012. The global diversity of birds in space and time. - Nature 491: 444-448.

696 Jezkova, T. and Wiens, J. J. 2017. What Explains Patterns of Diversification and Richness among

697 Animal Phyla? - Am. Nat. 189: 000-000.

698 Kennedy, J. D. et al. 2014. Into and out of the tropics: The generation of the latitudinal gradient among New World passerine birds. - J. Biogeogr. 41: 1746-1757.

700 Kerr, J. T. and Currie, D. J. 1999. The relative importance of evolutionary and environmental 701 controls on broad-scale patterns of species richness in North America. - Ecoscience 6: 329$302 \quad 337$

Landis, M. J. et al. 2013. Bayesian analysis of biogeography when the number of areas is large. -

$704 \quad$ Syst. Biol. 62: 789-804.

705 Latham, R. E. and Ricklefs, R. E. 1993. Global Patterns of Tree Species Richness in Moist Forests:

706 Energy-Diversity Theory Does Not Account for Variation in Species Richness. - Oikos 67:

$707 \quad 325-333$

708 Leidinger, L. and Cabral, J. S. 2017. Biodiversity dynamics on Islands: Explicitly accounting for 709 causality in mechanistic models. - Diversity 9: 30.

710 Lewitus, E. and Morlon, H. 2017. Detecting environment-dependent diversification from 711 phylogenies: a simulation study and some empirical illustrations. - Syst. Biol. in press. 
712 Looney, B. P. et al. 2016. Into and out of the tropics: Global diversification patterns in a

713 hyperdiverse clade of ectomycorrhizal fungi. - Mol. Ecol. 25: 630-647.

714 Losos, J. B. and Schluter, D. 2000. Analysis of an evolutionary species-area relationship. - Nature $715 \quad 408: 847-50$.

716 Magallón, S. and Sanderson, M. J. 2001. Absolute diversification rates in angiosperm clades. $717 \quad$ Evolution 55: 1762-80.

Marshall, C. R. 2017. Five palaeobiological laws needed to understand the evolution of the living biota. - Nat. Ecol. Evol. 1: 165. diversification and the need to incorporate time-varying carrying capacities. - Philos. Trans.

Matzke, N. J. 2014. Model selection in historical biogeography reveals that founder-event speciation is a crucial process in island clades. - Syst. Biol. 63: 951-970.

McGaughran, A. 2015. Integrating a Population Genomics Focus into Biogeographic and Macroecological Research. - Front. Ecol. Evol. 3: 1-5. Varying Environments. - Am. Nat. 140: 1010-1027. new methods and software. - Ecography (Cop.). 40: 461-477. 
733 Morinière, J. et al. 2016. Phylogenetic niche conservatism explains an inverse latitudinal diversity

734 gradient in freshwater arthropods. - Sci. Rep. 6: 1-12.

735 Morlon, H. 2014. Phylogenetic approaches for studying diversification. - Ecol. Lett. 17: 508-25.

736 Morlon, H. et al. 2010. Inferring the dynamics of diversification: a coalescent approach. - PLoS

$737 \quad$ Biol. in press.

738 Nee, S. 2006. Birth-Death Models in Macroevolution. - Annu. Rev. Ecol. Evol. Syst. 37: 1-17.

739 Nee, S. et al. 1994. The reconstructed evolutionary process. - Philos. Trans. R. Soc. Lond. B. Biol.

$740 \quad$ Sci. 344: 305-11.

741 Omland, K. E. et al. 2008. Tree thinking for all biology: the problem with reading phylogenies as

742 ladders of progress. - BioEssays 30: 854-67.

743 Paper, S. et al. 2006. Likelihood Methods for Detecting Temporal Shifts in Diversification Rates. -

$744 \quad$ Evolution (N. Y). 60: 1152.

745 Paper, S. et al. 2016. Past, future, and present of state-dependent models of diversification. - Am.

746 J. Bot. 103: 792-795.

747 Paper, S. et al. 2017. Accelerated body size evolution during cold climatic periods in the Cenozoic.

748 - Proc. Natl. Acad. Sci. 114: 4183-4188.

749 Pärtel, M. et al. 2016. Macroecology of biodiversity: disentangling local and regional effects. -

$750 \quad$ New Phytol. 211: 404-410.

751 Pérez-Escobar, O. A. et al. 2017. Recent origin and rapid speciation of Neotropical orchids in the 752 world's richest plant biodiversity hotspot. - New Phytol. 215: 891-905. 
753 Pinto-Ledezma, J. N. et al. 2017. The geographical diversification of Furnariides: the role of forest

754 versus open habitats in driving species richness gradients. - J. Biogeogr. 44: 1683-1693.

755 Poe, S. et al. Comparative evolution of an archetypal adaptive radiation: Innovation and

756 opportunity in Anolis lizards. - Am. Nat. in press.

757 Poe, S. et al. 2017. A Phylogenetic, Biogeographic, and Taxonomic study of all Extant Species of

$758 \quad$ Anolis (Squamata; Iguanidae). - Syst. Biol. 0: 1-35.

759 Pulido-Santacruz, P. and Weir, J. T. 2016. Extinction as a driver of avian latitudinal diversity

760 gradients. - Evolution (N. Y). 70: 860-872.

761 Pyron, R. A. 2014a. Biogeographic analysis reveals ancient continental vicariance and recent

762 oceanic dispersal in amphibians. - Syst. Biol. 63: 779-797.

763 Pyron, R. A. 2014b. Biogeographic Analysis Reveals Ancient Continental Vicariance and Recent

764 Oceanic Dispersal in Amphibians. - Syst. Biol. 63: 779-797.

765 Pyron, R. A. 2014C. Temperate extinction in squamate reptiles and the roots of latitudinal

766 diversity gradients. - Glob. Ecol. Biogeogr. 23: 1126-1134.

767 Qian, H. et al. 2014. Evolutionary and ecological causes of species richness patterns in North

768 American angiosperm trees. - Ecography (Cop.).: 1-10.

769 Qian, H. et al. 2015. Evolutionary and ecological causes of species richness patterns in North

$770 \quad$ American angiosperm trees. - Ecography (Cop.). 38: 241-250.

771 Quental, T. B. and Marshall, C. R. 2010. Diversity dynamics: molecular phylogenies need the fossil

772 record. - Trends Ecol. Evol. 25: 434-41. 
773 Rabosky, D. 2009. Ecological limits and diversification rate: alternative paradigms to explain the 774 variation in species richness among clades and regions. - Ecol. Lett. 12: 735-743.

775 Rabosky, D. L. 2010a. Extinction rates should not be estimated from molecular phylogenies. -

776 Evolution 64: 1816-24.

777 Rabosky, D. L. 2010b. Primary controls on species richness in higher taxa. - Syst. Biol. 59: 634-45.

778 Rabosky, D. L. 2012. Testing the time-for-speciation effect in the assembly of regional biotas. -

779 Methods Ecol. Evol. 3: 224-233.

780 Rabosky, D. L. 2013. Diversity-Dependence, Ecological Speciation, and the Role of Competition in 781 Macroevolution. - Annu. Rev. Ecol. Evol. Syst. 44: 481-502.

782 Rabosky, D. L. 2014. Automatic detection of key innovations, rate shifts, and diversity-

783 dependence on phylogenetic trees. - PLoS One in press.

784 Rabosky, D. L. 2016a. Reproductive isolation and the causes of speciation rate variation in nature.

785 - Biol. J. Linn. Soc. 118: 13-25.

786 Rabosky, D. L. 2016b. Challenges in the estimation of extinction from molecular phylogenies: A

787 response to Beaulieu and O'Meara. - Evolution (N. Y). 70: 218-228.

788 Rabosky, D. L. and Lovette, I. J. 2008. Density-dependent diversification in North American wood 789 warblers. - Proc. Biol. Sci. 275: 2363-71.

790 Rabosky, D. L. and Hurlbert, A. H. 2015. Species Richness at Continental Scales Is Dominated by 791 Ecological Limits. - Am. Nat. 185: 572-583.

792 Rabosky, D. L. and Goldberg, E. E. 2015. Model Inadequacy and Mistaken Inferences of Trait- 
Dependent Speciation. - Syst. Biol. 64: 340-355.

794 Rabosky, D. L. and Goldberg, E. E. 2017. FiSSE: A simple nonparametric test for the effects of a

795 binary character on lineage diversification rates. - Evolution (N. Y). 71: 1432-1442.

796 Rabosky, D. L. et al. 2014. BAMMtools: An R package for the analysis of evolutionary dynamics on

797 phylogenetic trees (S Kembel, Ed.). - Methods Ecol. Evol. 5: 701-707.

798 Rabosky, D. L. et al. 2015. Minimal effects of latitude on present-day speciation rates in New

799 World birds. - Proc. R. Soc. B Biol. Sci. 282: 20142889.

800 Ramiadantsoa, T. et al. 2017. Phylogenetic Comparative Method for Geographical Radiation. -

$801 \quad$ Ann. Zool. Fennici 54: 237-257.

802 Ree, R. H. et al. 2005. A likelihood framework for inferring the evolution of geographic range on

803 phylogenetic trees. - Evolution (N. Y). 59: 2299-311.

804 Robledo-Arnuncio, J. J. et al. 2014. Space, time and complexity in plant dispersal ecology. - Mov.

$805 \quad$ Ecol. 2:1-17.

806 Rolland, J. et al. 2014. Faster speciation and reduced extinction in the tropics contribute to the

807 mammalian latitudinal diversity gradient. - PLoS Biol. 12: e1001775.

808 Ronquist, F. 1997. Dispersal-vicariance analysis: a new approach to the quantification of historical

809 biogeography. - Syst. Bot. 46: 195-203.

810 Roy, K. and Goldberg, E. E. 2007. Origination, Extinction, and Dispersal: Integrative Models for

811 Understanding Present-Day Diversity Gradients. - Am. Nat. 170: S71-S85.

812 Sánchez-Ramírez, S. et al. 2015. In and out of refugia: Historical patterns of diversity and 

$593^{8-5956 . ~}$ and species-richness data. - Syst. Biol. 66: 367-378.

817 Sanmartin, I. et al. 2010. Bayesian island biogeography in a continental setting: the Rand Flora case. - Biol. Lett. 6: 703-707.

819 Sanmartín, I. 2012. Historical Biogeography: Evolution in Time and Space. - Evol. Educ. Outreach 5: $555-568$. timetrees to patterns of biotic assemblage. - Front. Genet. 7: 1-17.

823 Sanmartín, I. et al. 2008. Inferring dispersal: a Bayesian approach to phylogeny-based island 824 biogeography, with special reference to the Canary Islands. - J. Biogeogr. 35: 428-449.

825 Schluter, D. and Pennell, M. W. 2017. Speciation gradients and the distribution of biodiversity. $826 \quad$ Nature 546: 48-55.

827 Sepkoski, J. J. 1998. Rates of speciation in the fossil record. - Philos. Trans. R. Soc. Lond. B. Biol. Sci. 353: 315-26.

829 Silvestro, D. et al. 2014. Bayesian estimation of speciation and extinction from incomplete fossil occurrence data. - Syst. Biol. 63: 349-367.

831 Silvestro, D. et al. 2016. Fossil biogeography: a new model to infer dispersal, extinction and sampling from palaeontological data. - Philos. Trans. R. Soc. B Biol. Sci. 371: 20150225. 
833 Stadler, T. 2013. Recovering speciation and extinction dynamics based on phylogenies. 26: 1203$834 \quad 1219$.

835 Staggemeier, V. G. et al. 2015. Phylogenetic analysis in Myrcia section Aulomyrcia and inferences 836 on plant diversity in the Atlantic rainforest. - Ann. Bot. 115: 747-761.

837 Stephens, P. R. and Wiens, J. J. 2003. Explaining species richness from continents to communities: 838 the time-for-speciation effect in emydid turtles. - Am. Nat. 161: 112-28.

839 Templeton, A. R. 2008. The reality and importance of founder speciation in evolution. - BioEssays 30: $470-479$.

841 Valente, L. M. et al. 2015. Equilibrium and non-equilibrium dynamics simultaneously operate in 842 the Galápagos islands. - Ecol. Lett. 18: 844-852.

843 Velasco, J. A. 2018. Are Historical Biogeographical Events Able to Promote Biological

844 Diversification? - In: Levente, H. (ed), Pure and Applied Biogeography. InTechOpen, pp. 15$845 \quad 30$.

846 Velasco, J. A. et al. 2018. Climatic and evolutionary factors shaping geographical gradients of 847 species richness in Anolis lizards. - Biol. J. Linn. Soc. xx: 1-13.

848 Vellend, M. et al. 2010. Measuring phylogenetic biodiversity. - Front. Meas. Biol. Divers.: 194-207.

849 Wellborn, G. A. and Langerhans, R. B. 2015. Ecological opportunity and the adaptive 850 diversification of lineages. - Ecol. Evol. 5: 176-195.

851 Wiens, J. J. 2011. The Causes Of Species Richness Patterns Across Space, Time, And Clades And 852 The Role Of "Ecological Limits." - O. Rev. Biol. 86: 75-96. 
bioRxiv preprint doi: https://doi.org/10.1101/261867; this version posted February 8, 2018. The copyright holder for this preprint (which was not certified by peer review) is the author/funder. All rights reserved. No reuse allowed without permission.

853 Wiens, J. J. and Donoghue, M. J. 2004. Historical biogeography, ecology and species richness. -

854 Trends Ecol. Evol. 19: 639-44.

855 Wiens, J. J. and Graham, C. H. 2005. Niche conservatism: Integrating evolution, ecology, and

856 conservation biology. - Annu. Rev. Ecol. Evol. Syst. 36: 519-539.

857 Wiens, J. J. et al. 2006. Evolutionary and Ecological Causes of the Latitudinal Diversity Gradient in

858 Hylid Frogs: Treefrog Trees Unearth the Roots of High Tropical Diversity. - Am. Nat. 168:

$859 \quad 579-596$.

860 
861 Table 1: Phylogenetic metrics and explicit diversification approaches used in macroecological

862 studies to address evolutionary questions related with the geographical diversity gradients.

\begin{tabular}{|c|c|c|c|}
\hline Metric & Author & Description & Software / R \\
\hline MRD & $\begin{array}{l}\text { Kerr and Currie } \\
1999\end{array}$ & $\begin{array}{l}\text { MRD is calculated by counting the number of } \\
\text { nodes separating each terminal species in a } \\
\text { regional assemblage or cell from the tips to root } \\
\text { of the phylogenetic tree. This metric does not } \\
\text { need that trees be ultrametric or have branch } \\
\text { lengths. }\end{array}$ & metricTester \\
\hline
\end{tabular}

PD is calcultated by summing all the branch lengths of species co-occurring in a regional PD (residual) Faith 1992 assemblage or cell. Residual PD is obtained from an ordinary least square regression picante, metricTester, between PD and species richness.

pez

PSV is calculated from a matrix where their diagonal elements provide the evolutionary divergence (based on the branch lengths) of each terminal species from the root to the tips

Helmus et al. 2007, PSV Algar et al. 2009 of the tree, and the off-diagonal elements provide the degree of shared evolutionary history among species. Values close to zero picante, metricTester, indicates that all species in a regional assemblage or cell are very close related whereas values close to one indicate that species are not related.

DR is calculated as the inverse of a measure of evolutionary isolation (Redding \& Mooers 2006) which sum all the edge lengths from a species

mean DR Jetz et al. 2012 to the root of the tree. The inverse of this FiSSE evolutionary isolation metric therefore capture the level of splitting rate of each species (i.e., its path to a top).

The mean age of co-occurring species in a regional assemblage or cell simply is calculated Mean age Latham and Ricklefs 1993 tallying the age of each most recent common ancestor (MRCA) for each species and the None averaged. 


\begin{tabular}{|c|c|c|c|}
\hline GeoSSE & Goldberg et al. 2011 & $\begin{array}{l}\text { The geographic state speciation and extinction } \\
\text {-GeoSSE- model is a trait-dependent } \\
\text { diversification method linking geographic } \\
\text { occurrence with diversification rates. These } \\
\text { method allow to infer both speciation and } \\
\text { extinction rates as movement (dispersal) rates } \\
\text { among two regions. }\end{array}$ & Diversitree R package \\
\hline BAMM & Rabosky 2014 & $\begin{array}{l}\text { BAMM is a method that attempt to identify } \\
\text { whether a phylogeny exhibit a single or various } \\
\text { macroevolutionary regimes (i.e., different } \\
\text { diversification dynamics). As speciation, } \\
\text { extinction and net diversification rates are } \\
\text { considered to be heterogeneous across the } \\
\text { phylogeny it is possible to estimate a rate for } \\
\text { each branch or species in the tree. }\end{array}$ & $\begin{array}{l}\text { BAMM software and } \\
\text { BAMMtools } \mathrm{R} \\
\text { package }\end{array}$ \\
\hline
\end{tabular}




\begin{tabular}{|c|c|c|c|c|c|}
\hline Hypothesis & References & Description & Predictions & $\begin{array}{c}\text { Metrics and/or } \\
\text { methods used } \\
\text { to test }\end{array}$ & Limitations \\
\hline $\begin{array}{l}\text { Phylogenetic } \\
\text { niche } \\
\text { conservatism } \\
\text { (PNC) }\end{array}$ & $\begin{array}{l}\text { Wiens and } \\
\text { Graham } \\
2005\end{array}$ & $\begin{array}{l}\text { Phylogenetic } \\
\text { niche } \\
\text { conservatism is } \\
\text { the tendency of } \\
\text { related species to } \\
\text { inherit niche } \\
\text { requirements } \\
\text { from its the most } \\
\text { recent common } \\
\text { ancestors (Wiens } \\
\text { \& Graham 2005). }\end{array}$ & $\begin{array}{l}\text { PNC predicts that regions } \\
\text { where a clade originated } \\
\text { will accumulate more } \\
\text { species simply due to } \\
\text { more occupation time and } \\
\text { diversification rates tend } \\
\text { to be similar between } \\
\text { regions. The tropical } \\
\text { niche conservatism } \\
\text { hypothesis (TNC; Wiens } \\
\text { and Donoghue 2004) is } \\
\text { based on PNC to explain } \\
\text { differences in species } \\
\text { richness in tropical and } \\
\text { temperate regions. }\end{array}$ & $\begin{array}{l}\text { MRD, Mean } \\
\text { age, GeoSSE, } \\
\text { BAMM }\end{array}$ & $\begin{array}{l}\text { 1) MRD metric fails to capture spatially dynamics of } \\
\text { the balance of speciation and extinction and it is } \\
\text { very hard to establish whether species richness in a } \\
\text { region is only generated by higher speciation rates. } \\
\text { Furthermore, MRD does not capture dispersal } \\
\text { dynamic across regions and species richness in a } \\
\text { given region can be generated from only dispersals } \\
\text { from nearby regions (e.g., macroevolutionary sinks; } \\
\text { CITA). 2) Mean age provide partial is able to test the } \\
\text { role of PNC on geographical species richness } \\
\text { because only it is possible to establish which } \\
\text { regions have, in average, old clades and this not } \\
\text { reflects whether many speciation events occurred } \\
\text { there. 3) GeoSSE is potentially the only one } \\
\text { approach that allow to disentangle these three } \\
\text { process but it is only limited to two regions (e.g., } \\
\text { tropical vs. temperate). In addition, GeoSSE has } \\
\text { been criticized due its low statistical power (see } \\
\text { Rabosky and Goldberg 2015). }\end{array}$ \\
\hline
\end{tabular}




\begin{tabular}{|c|c|c|c|c|c|}
\hline $\begin{array}{l}\text { Regional } \\
\text { diversification } \\
\text { (RD) }\end{array}$ & $\begin{array}{l}\text { Buckley et } \\
\text { al. } 2010\end{array}$ & $\begin{array}{l}\text { Differences in the } \\
\text { balance of } \\
\text { speciation and } \\
\text { extinction across } \\
\text { geography can } \\
\text { explain } \\
\text { differences in } \\
\text { species richness } \\
\text { between regions. }\end{array}$ & $\begin{array}{l}\text { RD predicts that regions } \\
\text { with striking differences in } \\
\text { species richness are due } \\
\text { to differences in } \\
\text { macroevolutionary } \\
\text { dynamics between } \\
\text { regions. }\end{array}$ & $\begin{array}{l}\text { residual PD, } \\
\text { GeoSSE, } \\
\text { BAMM }\end{array}$ & $\begin{array}{l}\text { 1) Residual PD can be used to discriminate regions } \\
\text { with rapid and slow diversification based on the } \\
\text { expected phylogenetic diversity given species } \\
\text { richness (Buckley et al. 2010). However, this metric } \\
\text { ignores the contribution to dispersal to PD in a given } \\
\text { region or cell. 2) GeoSSE can estimate speciation, } \\
\text { extinction and dispersal rates between regions but } \\
\text { again is limited to two regions. 3) BAMM potentially } \\
\text { could be used to estimate speciation rates for } \\
\text { regional clades but this method is unable to } \\
\text { estimate dispersal rates between regions. }\end{array}$ \\
\hline $\begin{array}{l}\text { Out of the } \\
\text { tropics (OTT) }\end{array}$ & $\begin{array}{l}\text { Jablonski et } \\
\text { al. } 2006\end{array}$ & $\begin{array}{l}\text { Species were } \\
\text { generated in the } \\
\text { tropical regions } \\
\text { and dispersed to } \\
\text { extratropical } \\
\text { regions but } \\
\text { maintain its } \\
\text { presence in its } \\
\text { ancestral areas }\end{array}$ & $\begin{array}{l}\text { High rates of speciation } \\
\text { are predicted in tropical } \\
\text { regions in contrast with } \\
\text { temperate regions. } \\
\text { Asymmetric dispersal } \\
\text { have occurred along the } \\
\text { biogeographical history of } \\
\text { a taxa from tropical to } \\
\text { temperate areas. }\end{array}$ & $\begin{array}{l}\text { MRD, Mean } \\
\text { age, GeoSSE }\end{array}$ & $\begin{array}{l}\text { These metrics are the same used to test the } \\
\text { PNC/TNC hypothesis as we discuss above. }\end{array}$ \\
\hline $\begin{array}{l}\text { Time for } \\
\text { speciation } \\
\text { effect (TEE) }\end{array}$ & $\begin{array}{l}\text { Stephens } \\
\text { and Wiens } \\
2003\end{array}$ & $\begin{array}{l}\text { Tropical regions } \\
\text { accumulated } \\
\text { more species } \\
\text { because their } \\
\text { clades had more } \\
\text { time to speciate } \\
\text { than temperate } \\
\text { regions. }\end{array}$ & $\begin{array}{l}\text { Regions recently } \\
\text { colonized had lower } \\
\text { species richness than } \\
\text { regions where clades } \\
\text { colonized very early in the } \\
\text { history of a clade. }\end{array}$ & Mean age & $\begin{array}{l}\text { 1) Mean age does not provide an accurate } \\
\text { description of which lineages colonized first a } \\
\text { region. To test this hypothesis, it might be } \\
\text { necessary to perform an ancestral range } \\
\text { reconstruction of all co-occurring clades and } \\
\text { estimate its diversification rates (i.e., total } \\
\text { diversification for each independent colonized clade; } \\
\text { Rabosky 2009; 2012). }\end{array}$ \\
\hline
\end{tabular}


864 Table 3. Parameter estimates from the GeoSSE model for three taxonomic groups (Furnariides birds, 865 hylid frogs, and Anolis lizards) across two regions. Areas for each taxonomic group as follows:

866 Furnariides birds: A: Forest; B: Open areas; Hylid frogs: A: Extra tropics; B: Tropics; Anolis lizards: A:

867 Islands; B: Mainland.

\begin{tabular}{ccccc}
\hline Group & Rates & A & B & AB \\
\hline \multirow{2}{*}{ Furnariides birds } & Speciation & $0.139 \pm 0.020$ & $0.223 \pm 0.065$ & $0.041 \pm 0.020$ \\
& Extinction & $0.040 \pm 0.025$ & $0.107 \pm 0.075$ & - \\
Dispersal & $0.021 \pm 0.004$ & $0.311 \pm 0.114$ & - \\
& Net diversification & $0.099 \pm 0.005$ & $0.116 \pm 0.01$ & - \\
\hline \multirow{2}{*}{ Hylid frogs } & Speciation & $0.044 \pm 0.003$ & $0.044 \pm 0.003$ & $0.041 \pm 0.025$ \\
& Extinction & $0.002 \pm 0.002$ & $0.002 \pm 0.002$ & - \\
& Dispersal & $0.001 \pm 0.001$ & $0.035 \pm 0.010$ & - \\
& Net diversification & $0.042 \pm 0.003$ & $0.042 \pm 0.003$ & - \\
\hline \multirow{2}{*}{ Anolis lizards } & Speciation & $0.058 \pm 0.003$ & $0.058 \pm 0.003$ & $1.245 \pm 1.303$ \\
& Extinction & $0.001 \pm 0.001$ & $0.001 \pm 0.001$ & - \\
& Dispersal & $0.002 \pm 0.001$ & $0.0003 \pm 0.000$ & -
\end{tabular}


869 Table 4. Frequency of dispersal events inferred using biogeographical stochastic mapping (BSM) for 870 three taxonomic groups (Furnariides birds, hylid frogs, and Anolis lizards) across two regions. Areas for

871 each taxonomic group as follows: Furnariides birds: A: Forest; B: Open areas; Hylid frogs: A: Extra

872 tropics; B: Tropics; Anolis lizards: A: Islands; B: Mainland.

873

\begin{tabular}{|c|c|c|c|c|}
\hline Event & Group & Regions & A & B \\
\hline \multirow{6}{*}{ Range expansions } & Furnariides birds & A & 0 & $92.62 \pm 4.39$ \\
\hline & & B & $31.4 \pm 4.29$ & 0 \\
\hline & Hylid frogs & $\mathbf{A}$ & 0 & $0.64 \pm 0.78$ \\
\hline & & B & $12.92 \pm 0.88$ & 0 \\
\hline & Anolis lizards & A & 0 & 0 \\
\hline & & B & 0 & 0 \\
\hline \multirow{6}{*}{ Founder events } & Furnariides birds & A & 0 & $24.46 \pm 2.54$ \\
\hline & & B & $10.88 \pm 2.22$ & 0 \\
\hline & Hylid frogs & A & 0 & $0.66 \pm 0.66$ \\
\hline & & B & $4.3 \pm 1.42$ & 0 \\
\hline & Anolis lizards & $\mathbf{A}$ & 0 & $2.02 \pm 0.14$ \\
\hline & & B & $0.12 \pm 0.33$ & 0 \\
\hline
\end{tabular}

874

875 
877 Figure 1. Diagram illustrating how differences in speciation, extinction, and dispersal rates between regions can generate a geographical species richness gradient. The phylogenetic trees below illustrate how the differences in speciation and extinction rates between two regional assemblages can shape a gradient of species richness (degraded blue colour).

881

Figure 2. Geographical patterns of some phylogenetic metrics used in macroecological studies to explore evolutionary process underlying geographical diversity gradients (see also Table 1 for a detailed explanation). Left column Anolis lizards; Middle column: Hylid frogs; Right column: Furnariides birds. (A-C) observed richness patterns; (D-F) rPD: residual phylogenetic diversity (i.e., after controlling for species richness); (G-I) PSV: phylogenetic species variability; (J-L) MRD: mean root distance; (M-O) MDR: mean diversification rate; $(P-R)$ Mean ages: average ages of species.

Figure 3. P-values distribution for each phylogenetic metric obtained through the null model (see main text for details). The vertical red lines represent the empirical 0.05 cut-off. Note that for all cases very few cells are below the 0.05 cut-off. (A-C) rPD: residual phylogenetic diversity (i.e., after controlling for species richness); (D-F) PSV: phylogenetic species variability; (G-I) MRD: mean root distance; (J-L) MDR: mean diversification rate; (M-O) Mean ages: average ages of species.

Figure 4. Variation of phylogenetic metric values for Furnariides birds in forest and open areas. rPD: residual phylogenetic diversity (i.e., after controlling for species richness); PSV: phylogenetic species variability; MRD: mean root distance; MDR: mean diversification rate; Mean ages: average ages of species.

Figure 5. Variation of phylogenetic metric values for Hylid frogs in tropics and extra-tropics regions. rPD: residual phylogenetic diversity (i.e., after controlling for species richness); PSV: phylogenetic species variability; MRD: mean root distance; MDR: mean diversification rate; Mean ages: average ages of species.

Figure 6. Variation of phylogenetic metric values for Anolis lizards in continental and insular areas. rPD: residual phylogenetic diversity (i.e., after controlling for species richness); PSV: phylogenetic species

907 variability; MRD: mean root distance; MDR: mean diversification rate; Mean ages: average ages of 908 species. 


\section{DIVERSITY GRADIENTS}

ligher speciation ower extinction Dispersal (out)

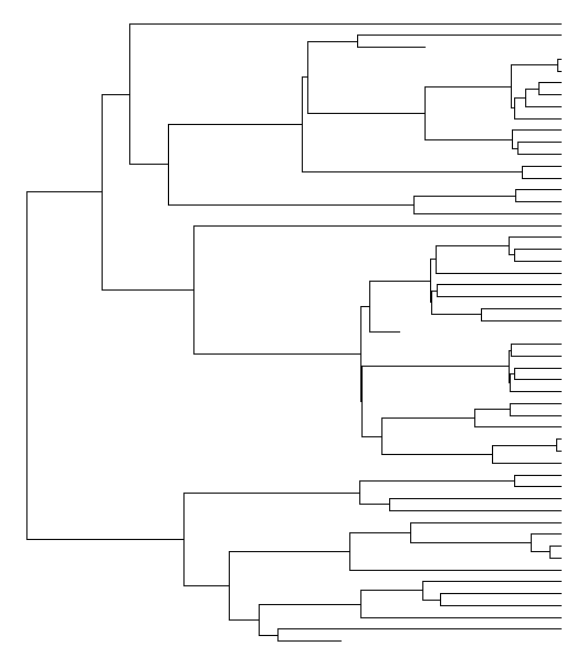

Speciation $=0.5 ;$ Extinction $=0.05$
Lower speciation Higher extinction Dispersal (in)

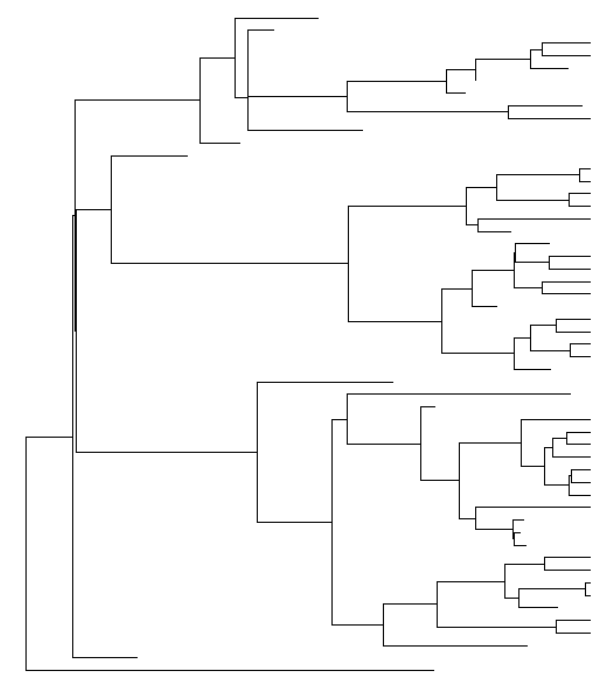

Speciation $=0.3 ;$ Extinction $=0.15$ 


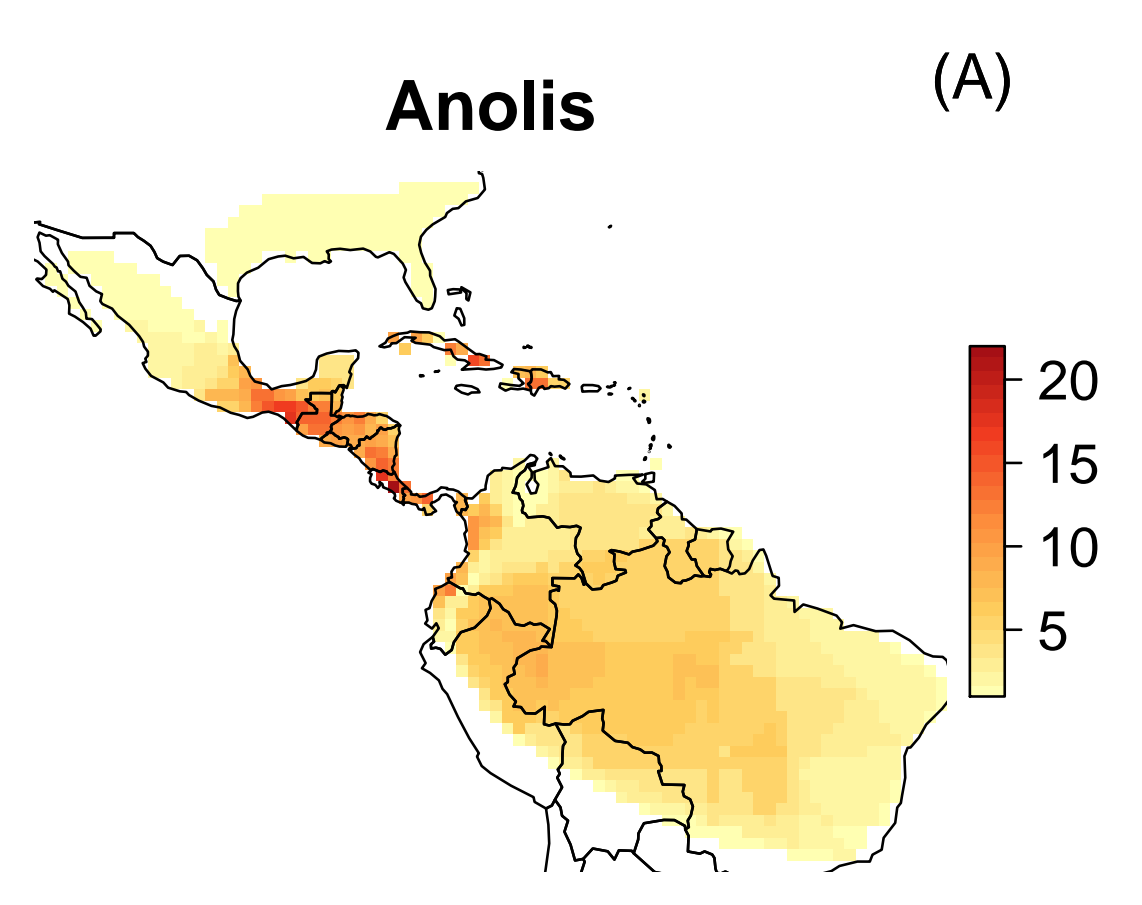

(D)

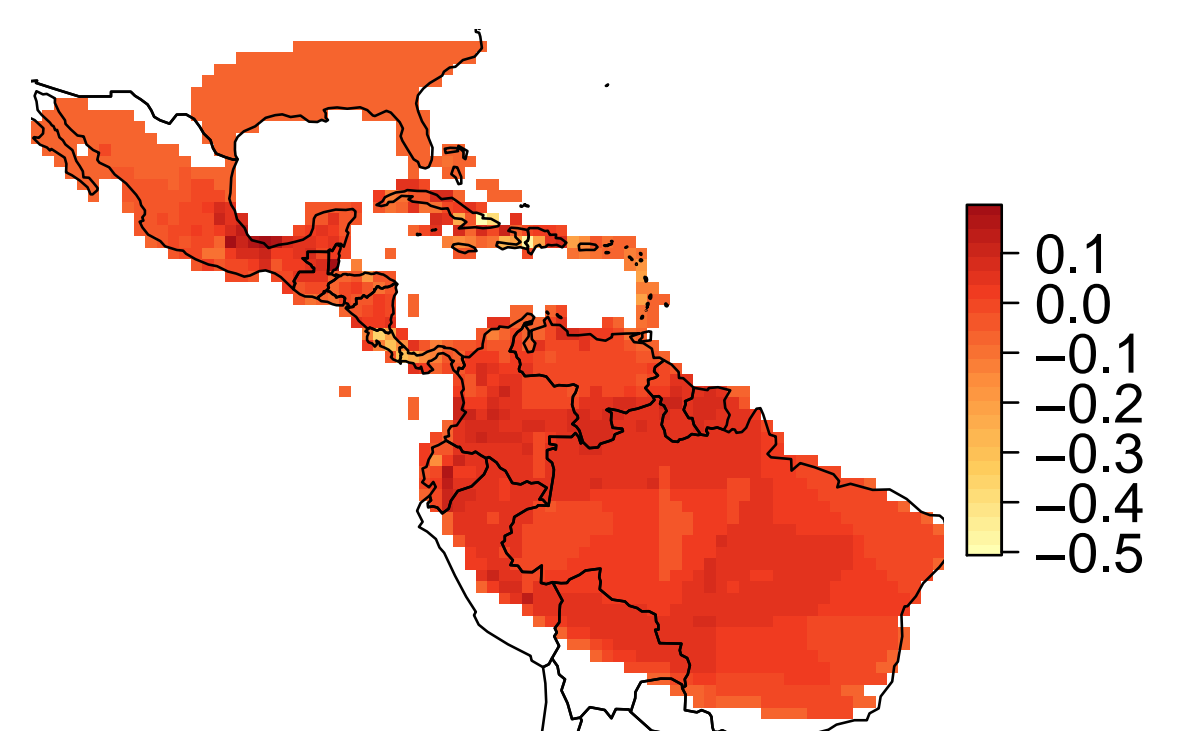

(G)

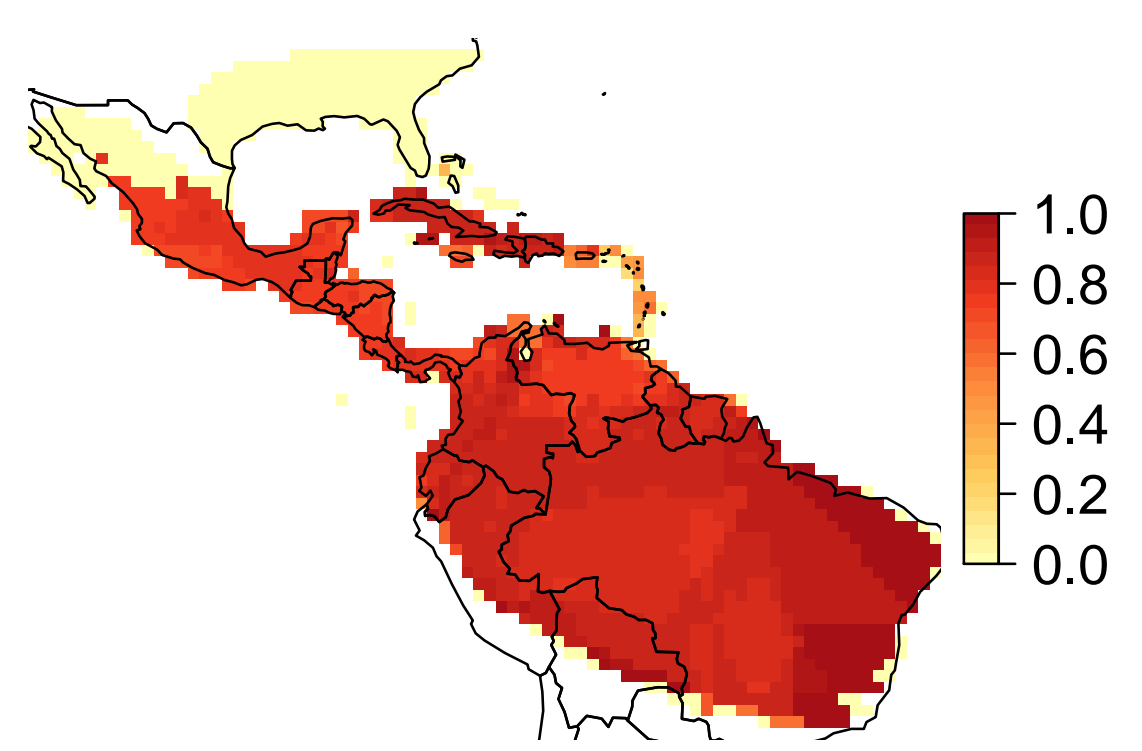

(J)

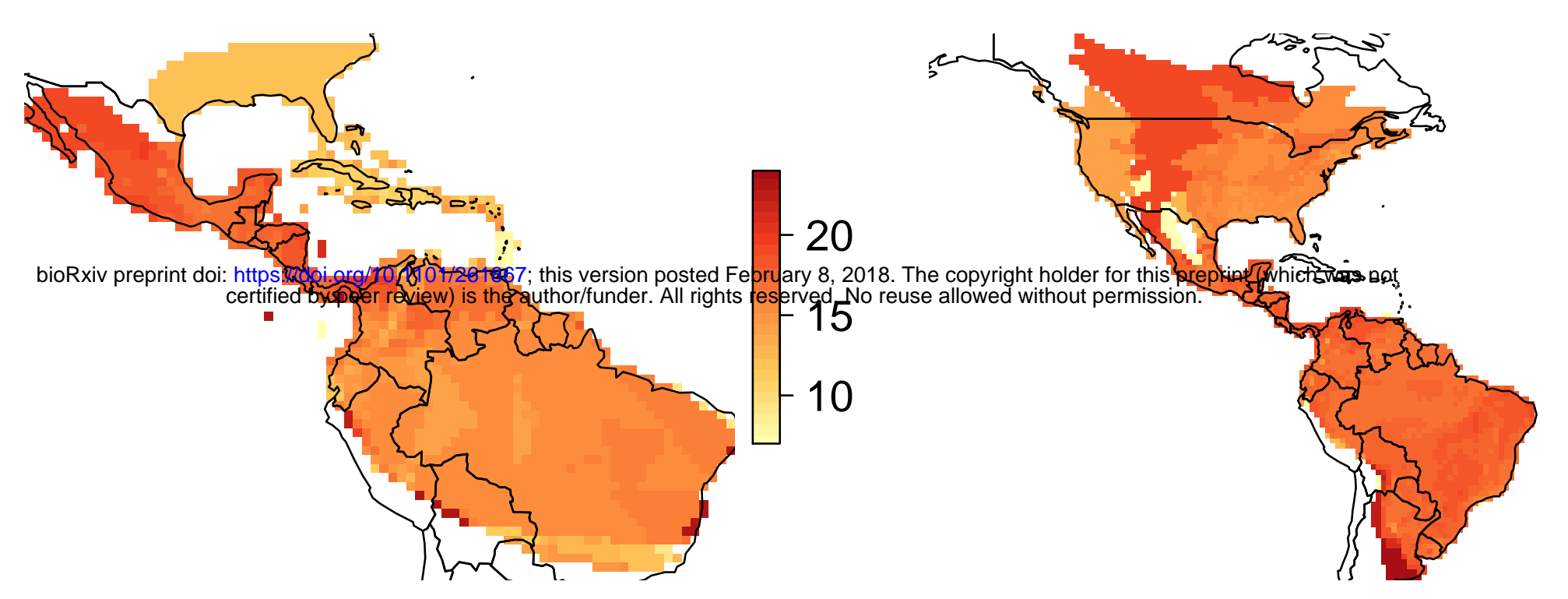

(M)

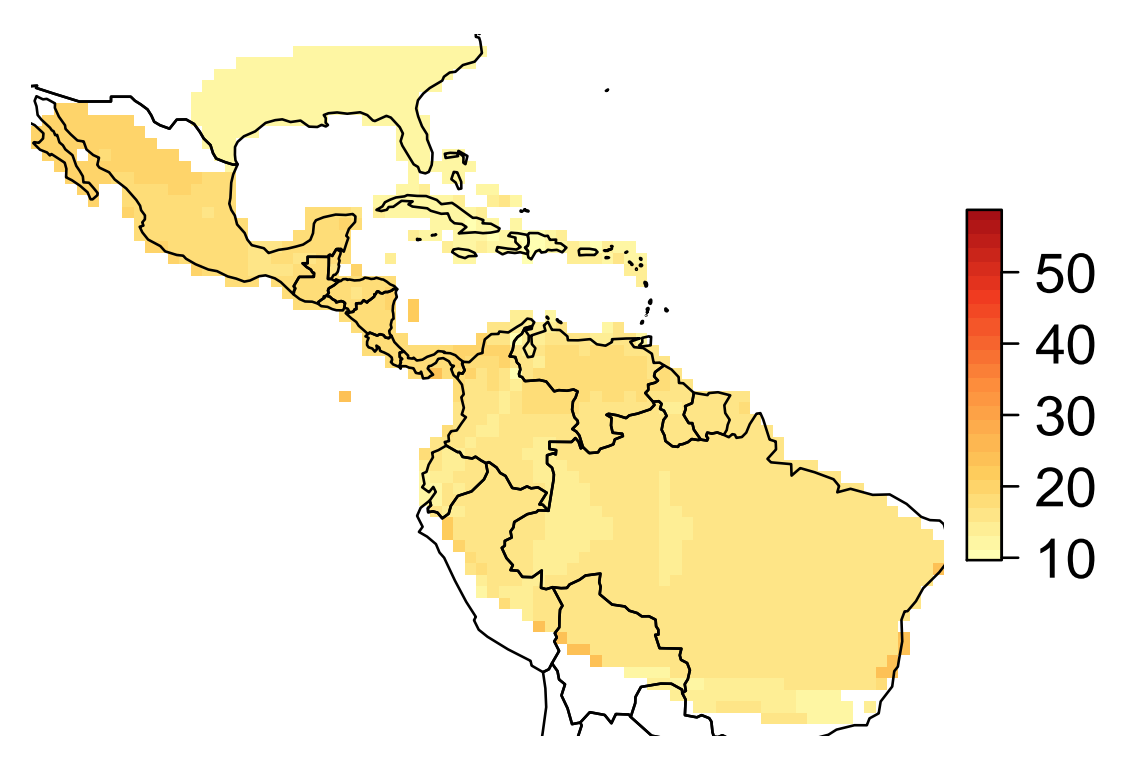

(P)

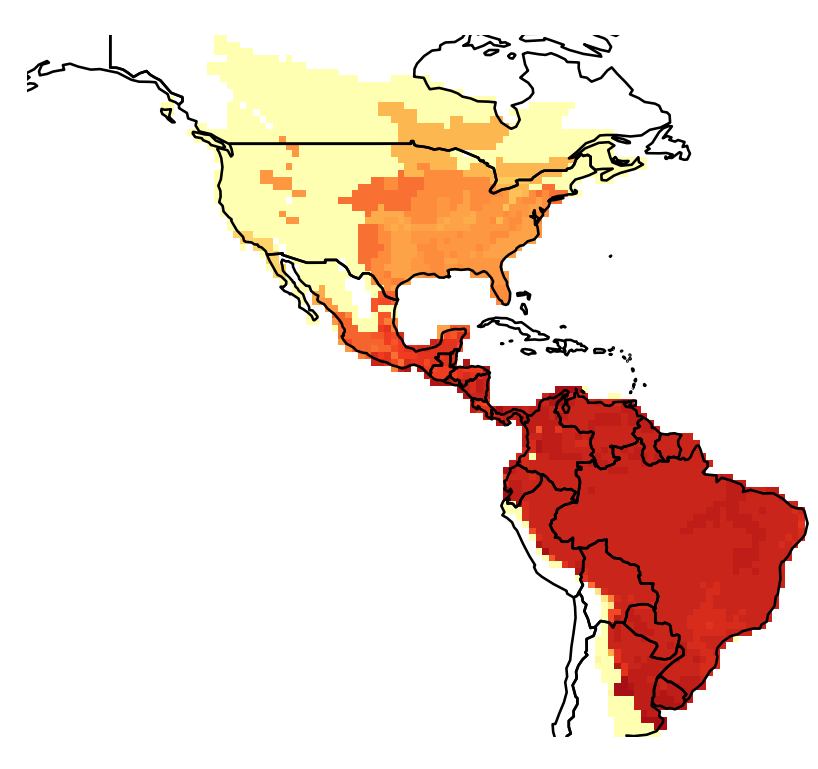

(K)

(N)

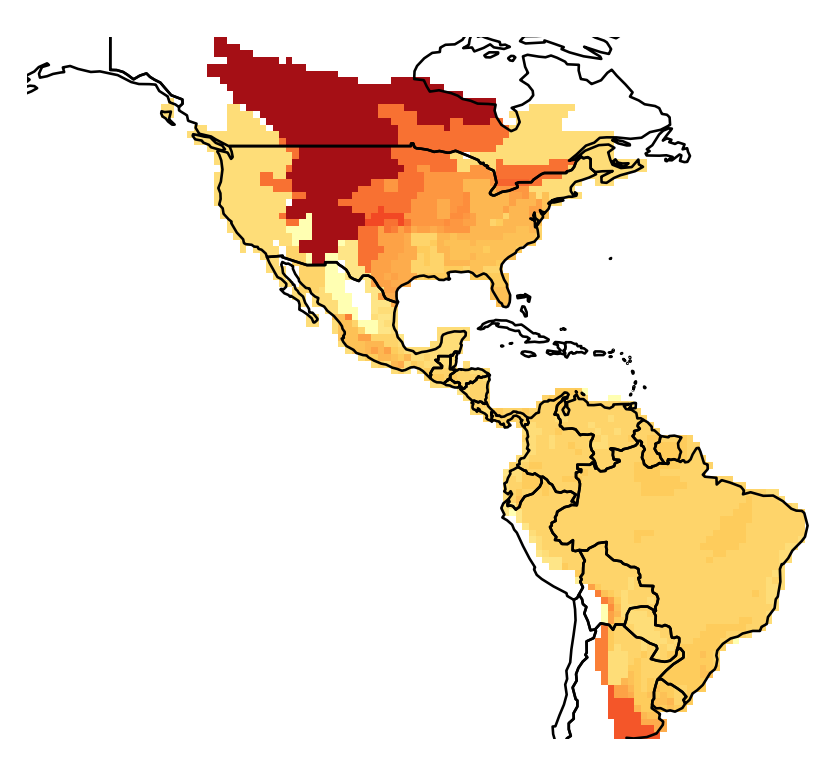

(Q)
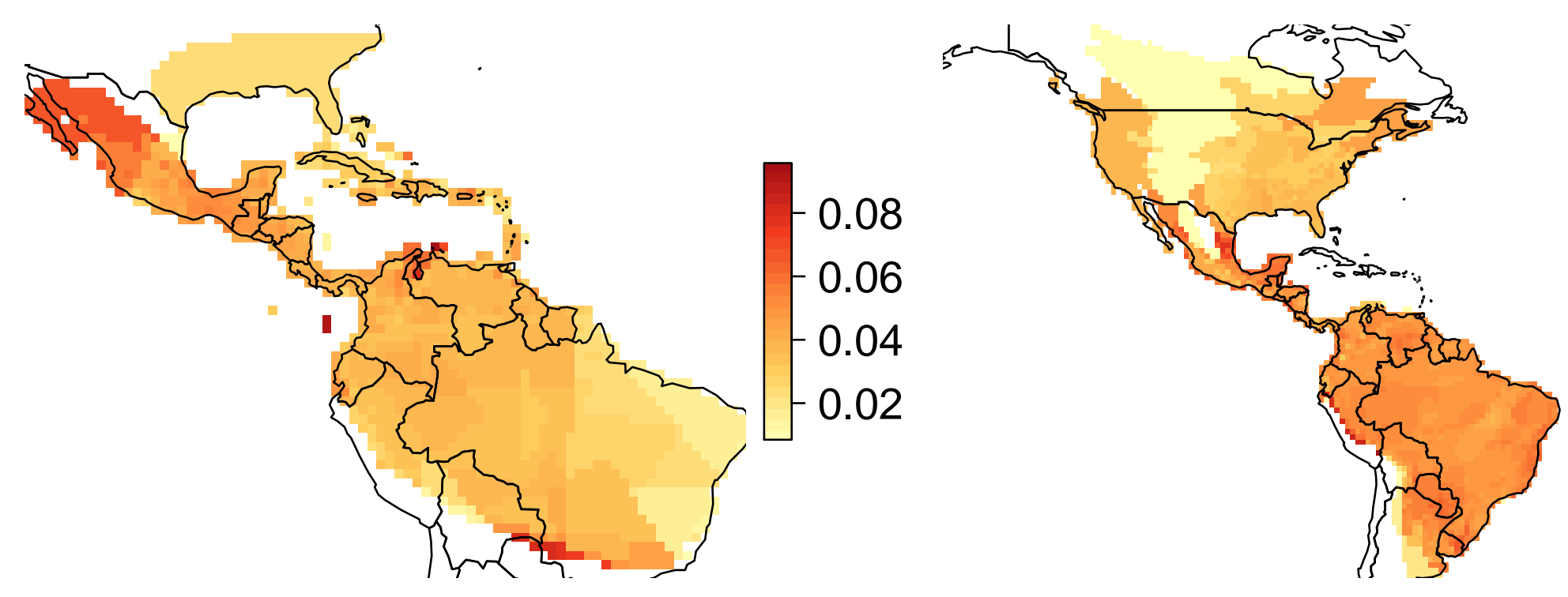

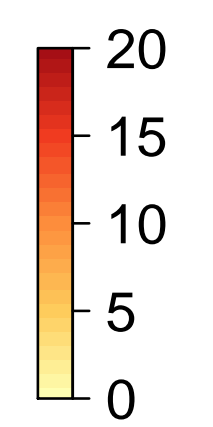

(B)

Furnariides

(C)

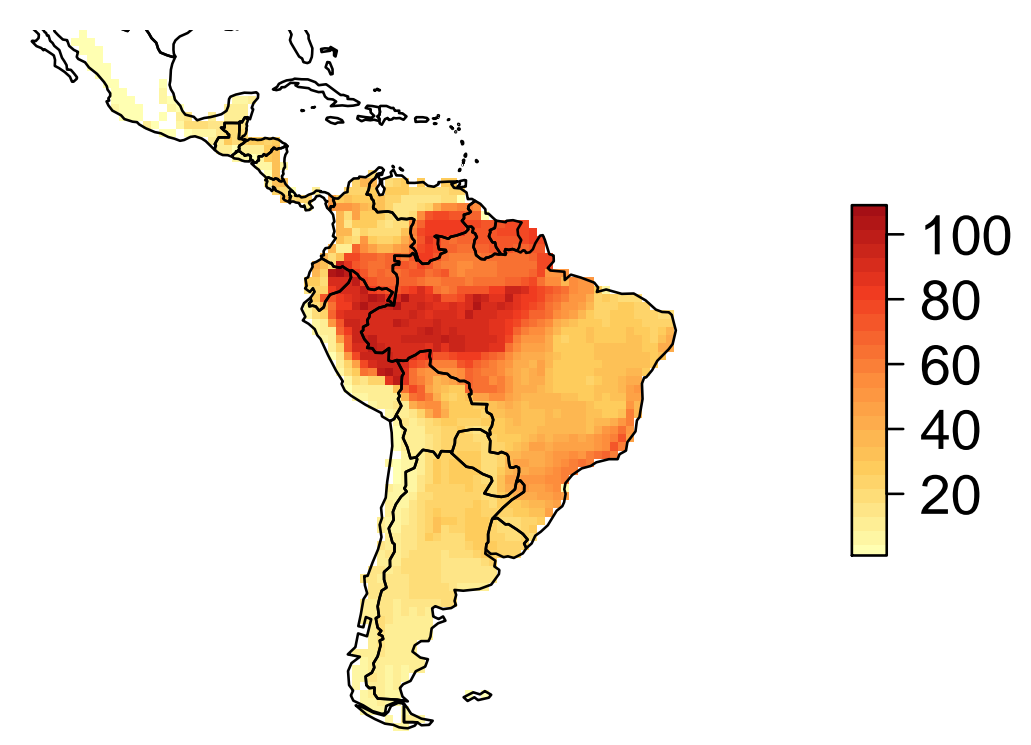

(F)

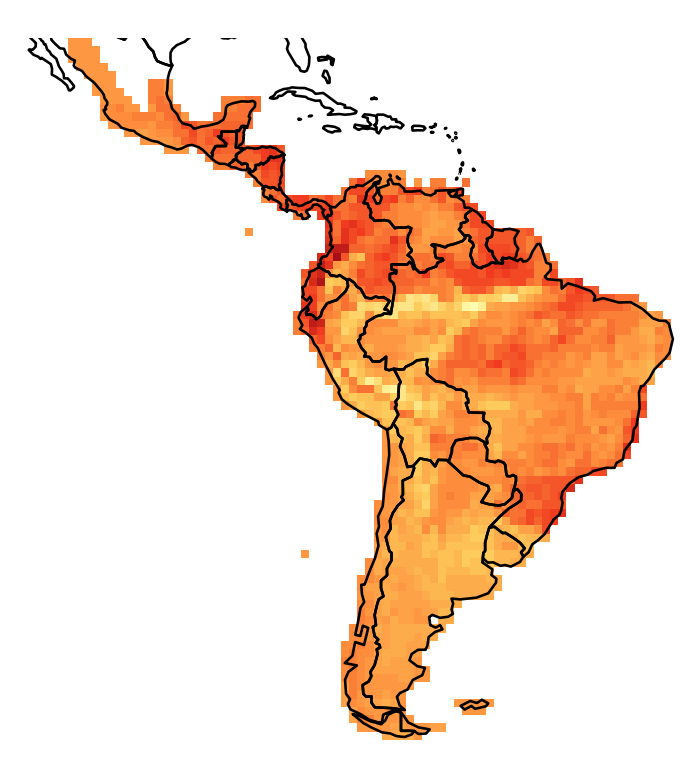

(I)

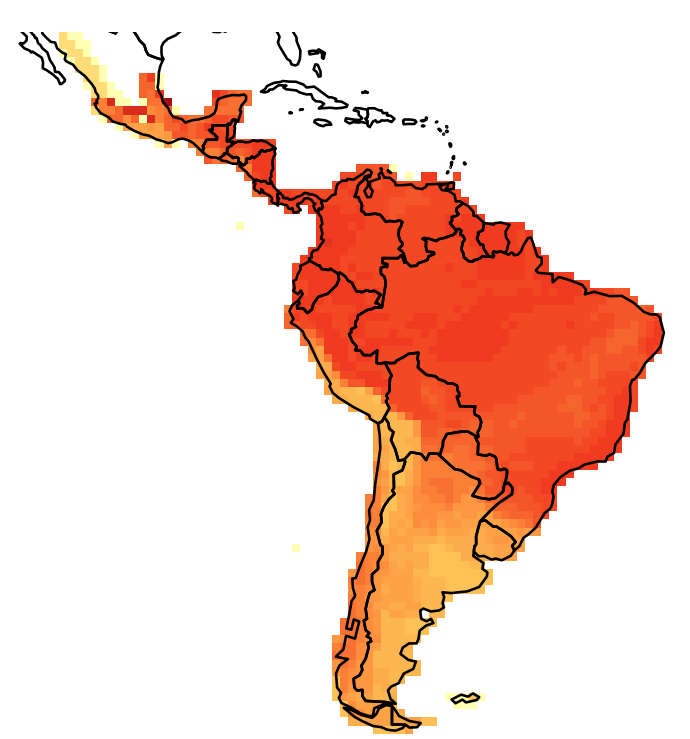

(L)

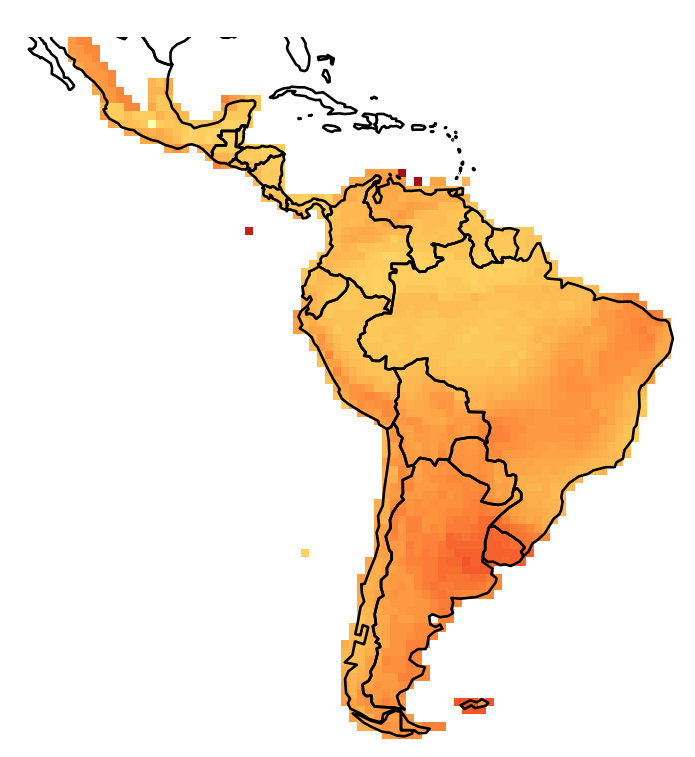

(O)

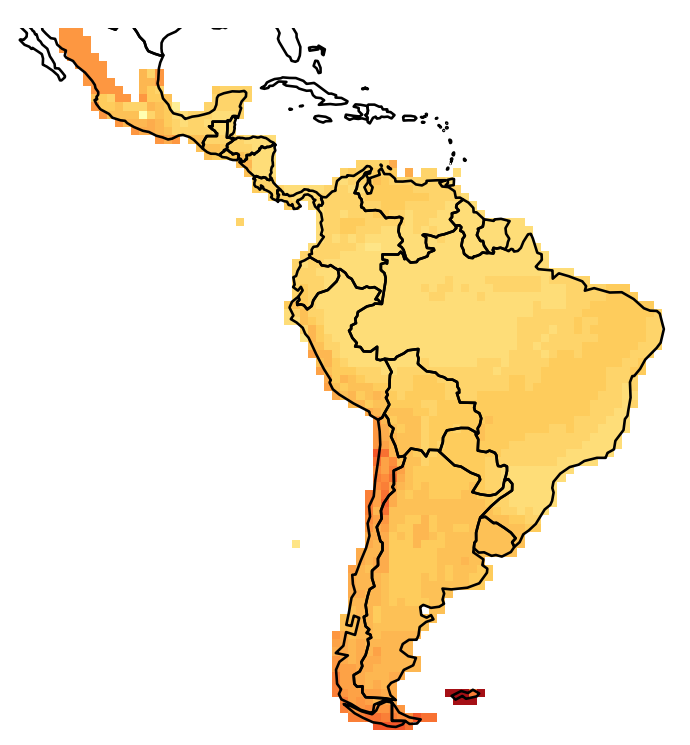

(R)

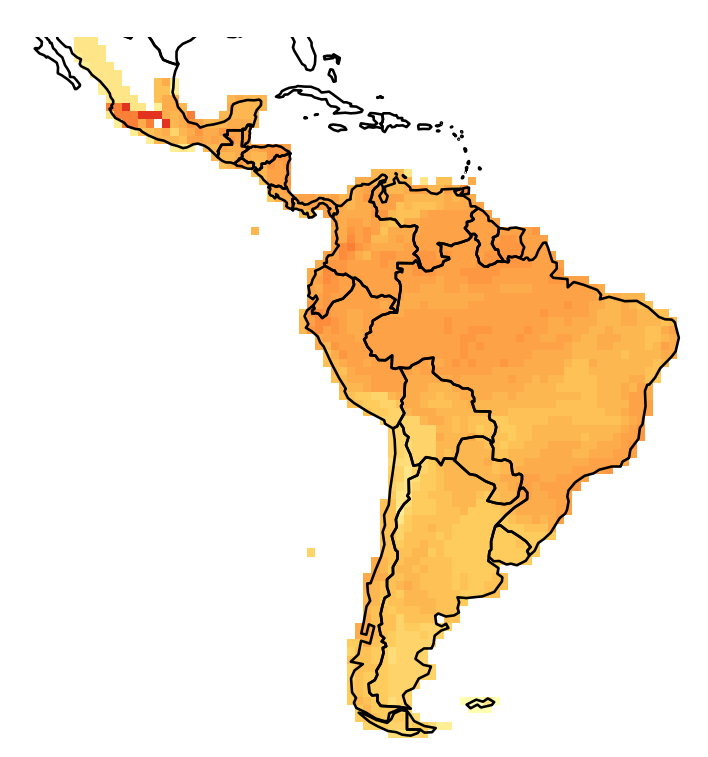

$\left[\begin{array}{r}1.0 \\ -0.8 \\ -0.6 \\ -0.4 \\ -0.2 \\ 0.0\end{array}\right.$

-25
-20
-15
-10

0.7
-0.6
-0.5
-0.4
-0.3
-0.2
-0.1

-14
-12
-10
-8
-6
-4
-2
35
-30
-25
-20
-15
-10
-5
0 
Anolis

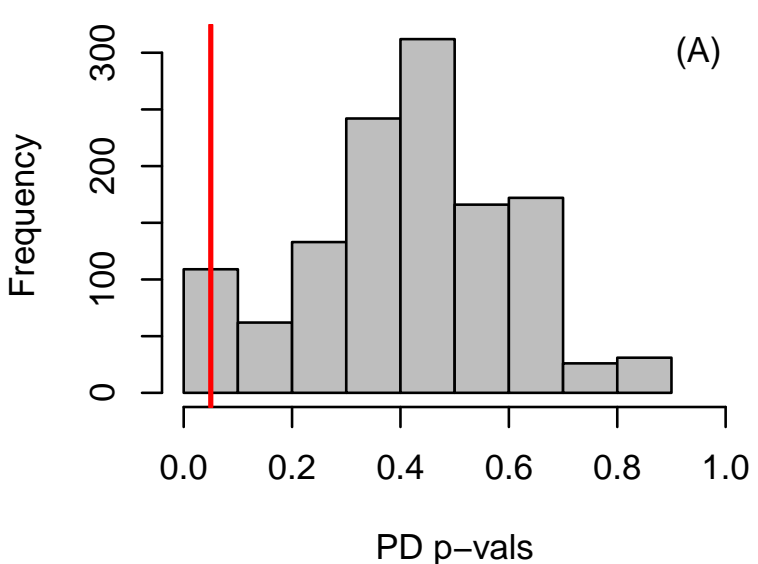

Hylids

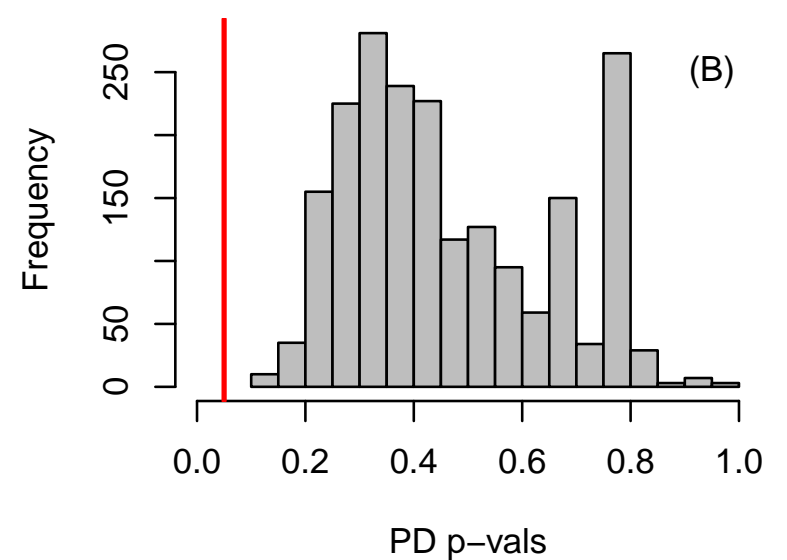

Furnariides

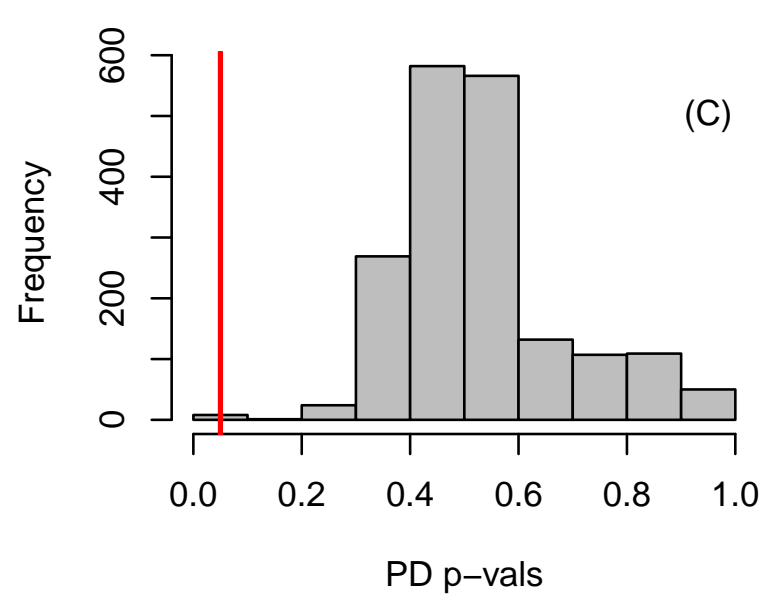

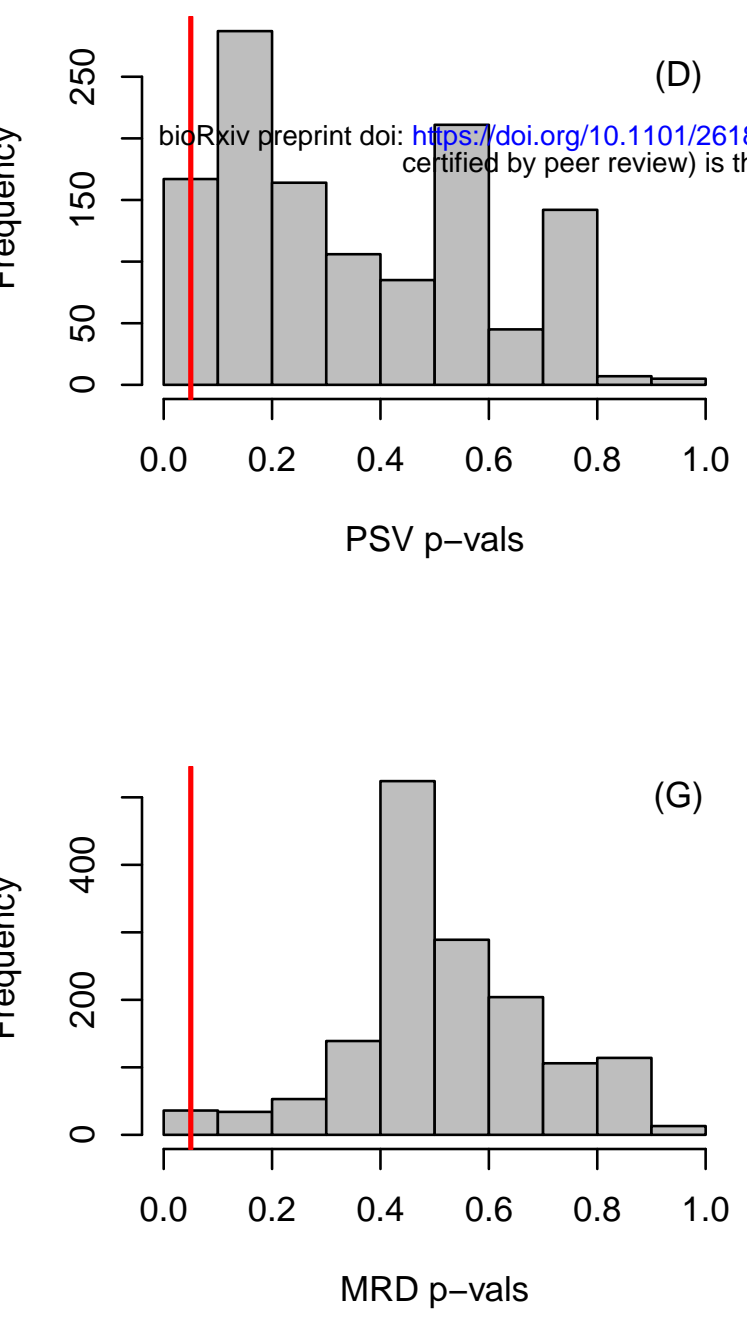

\& $\square+\square \quad \square$ (E)

E)

으.

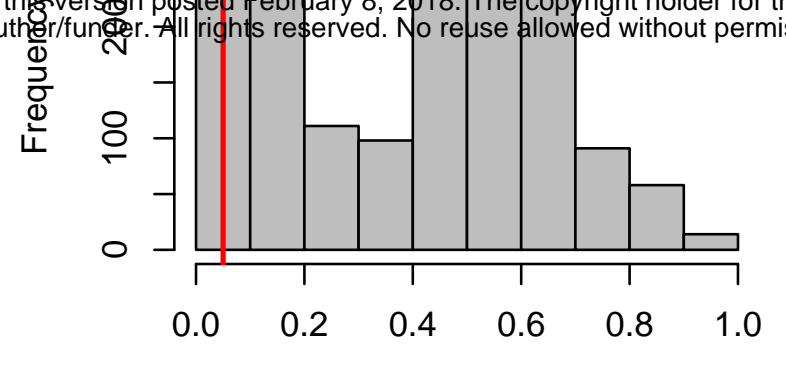

PSV p-vals
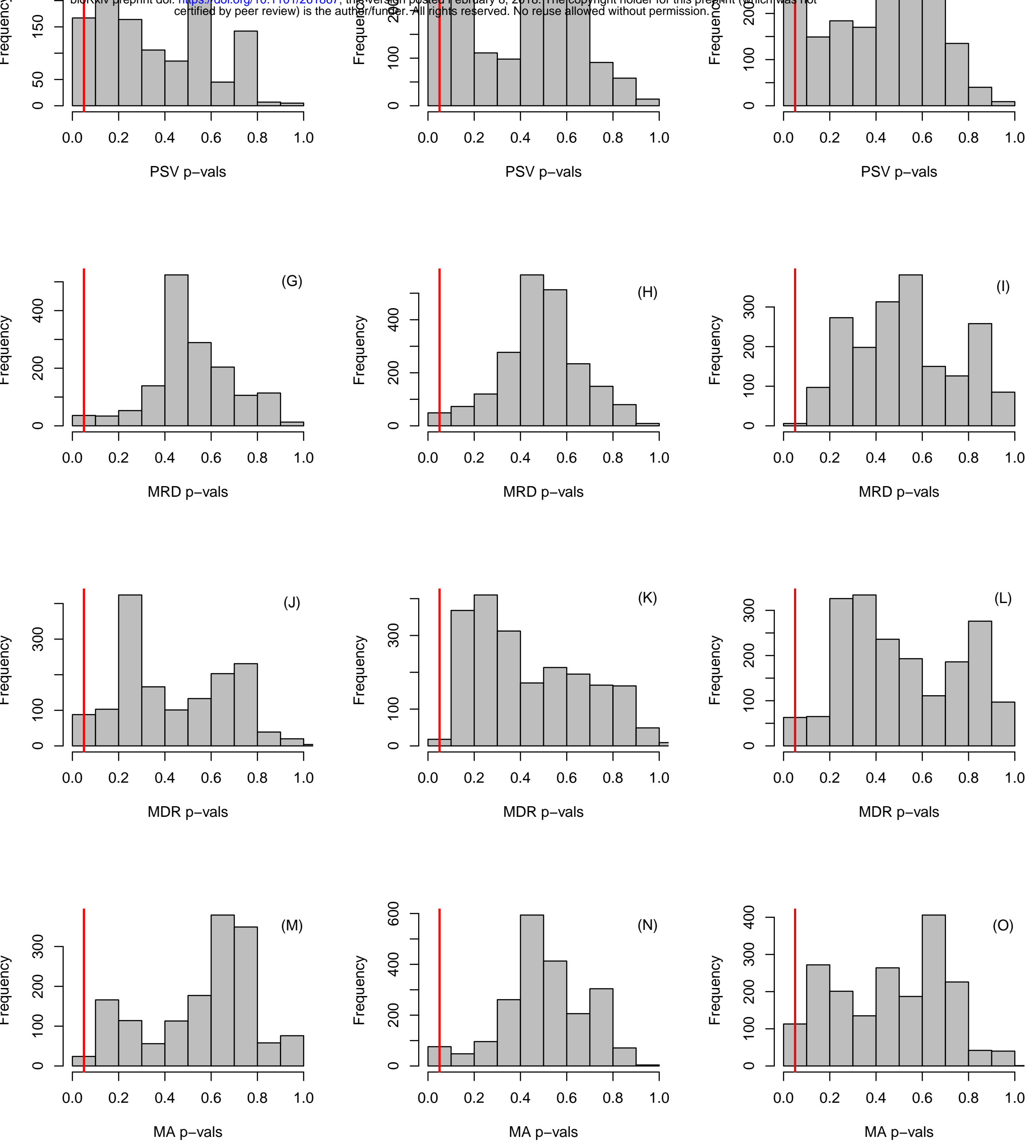

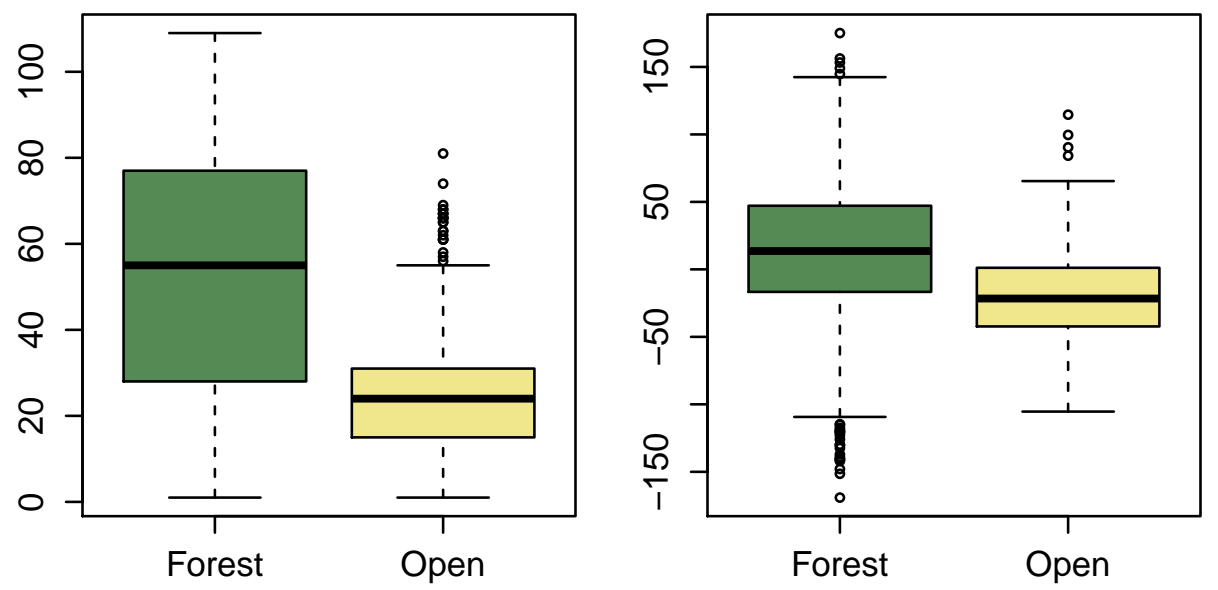

PSV

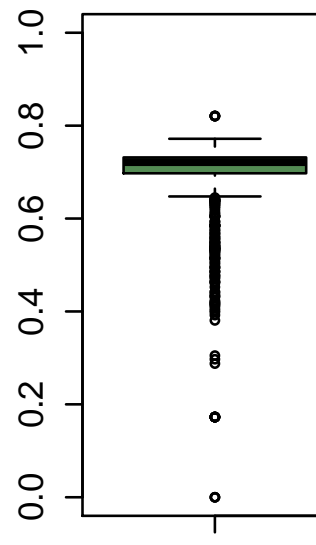

Forest

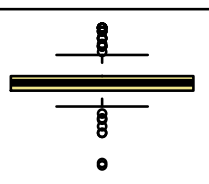

MDR

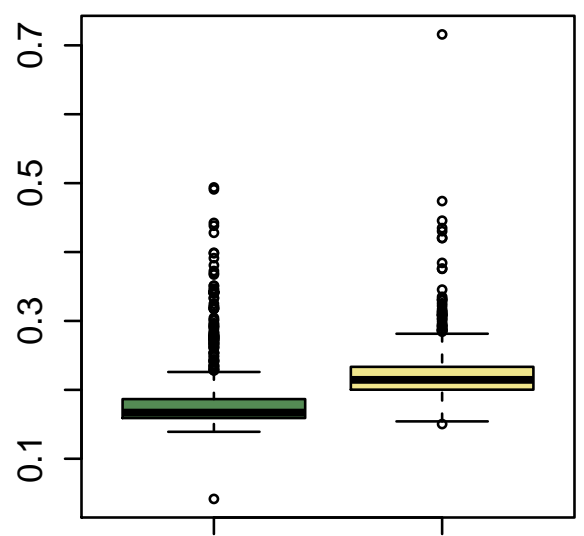

Forest
MRD

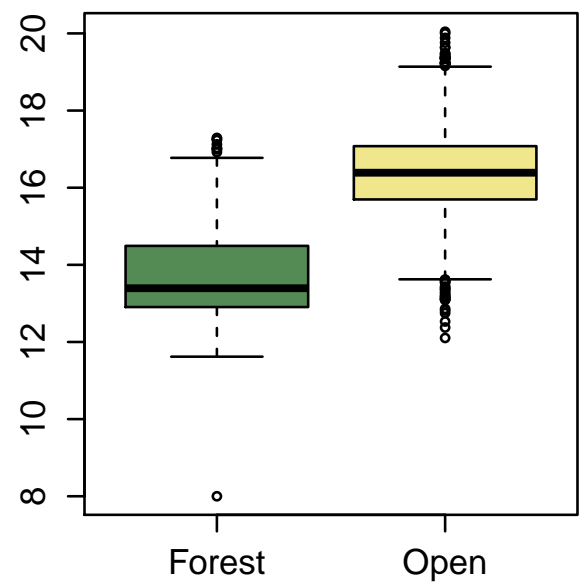

MA

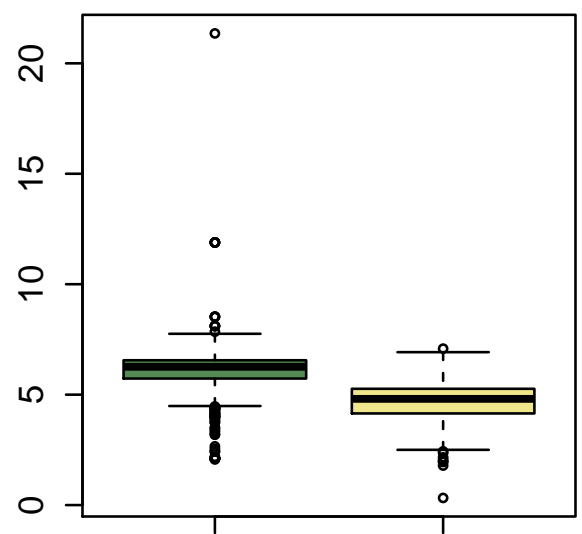

Forest 
Richness

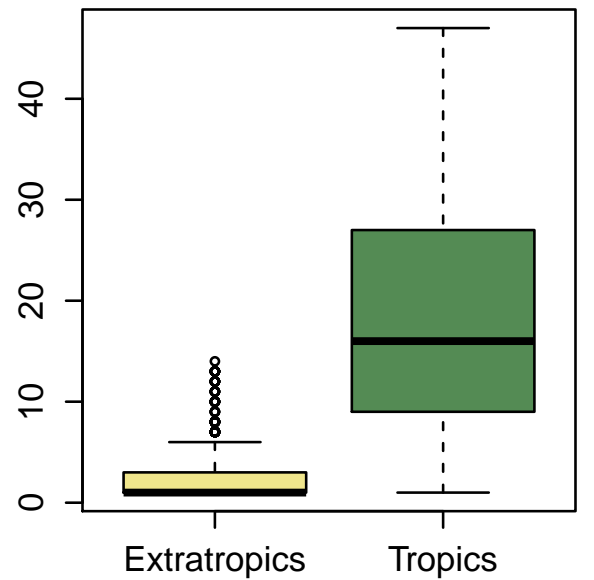

PSV

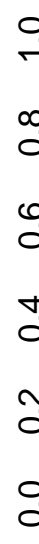

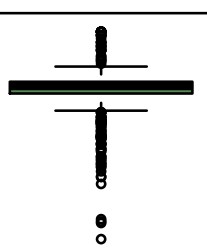

Extratropics Tropics

MDR

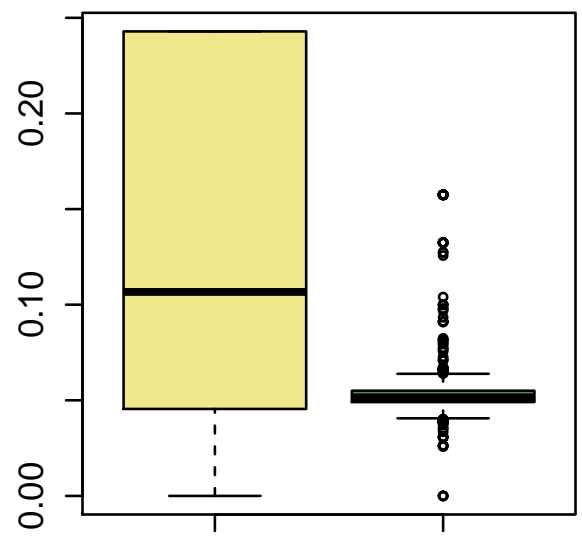

Extratropics

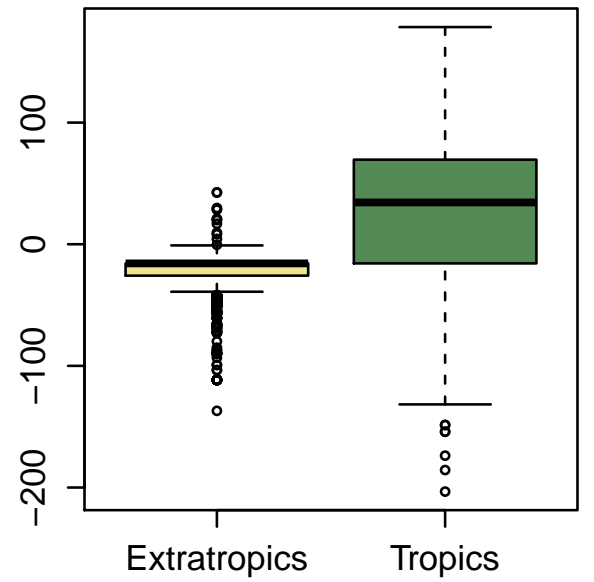

MRD

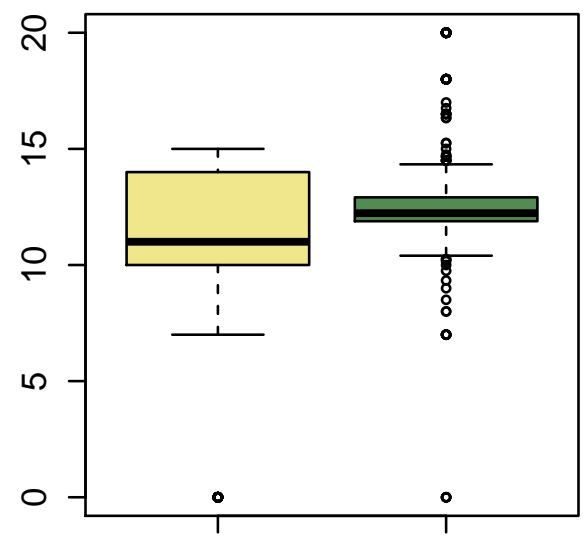

Extratropics Tropics

MA

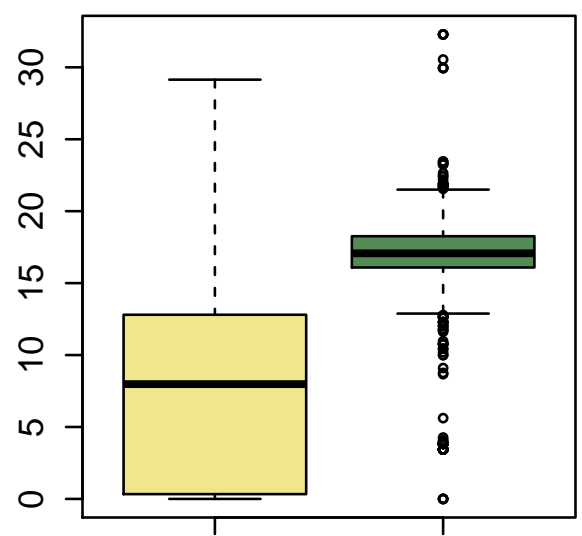

Extratropics Tropics 

bioRxiv preprint doi: https://doi.org/10.1101/261867; this version posted February 8, 2018. The copyright holder for this preprint (which was not
certified by peer review) is the author/funder. All rights reserved. No reuse allowed without permission.

\section{Anolis}

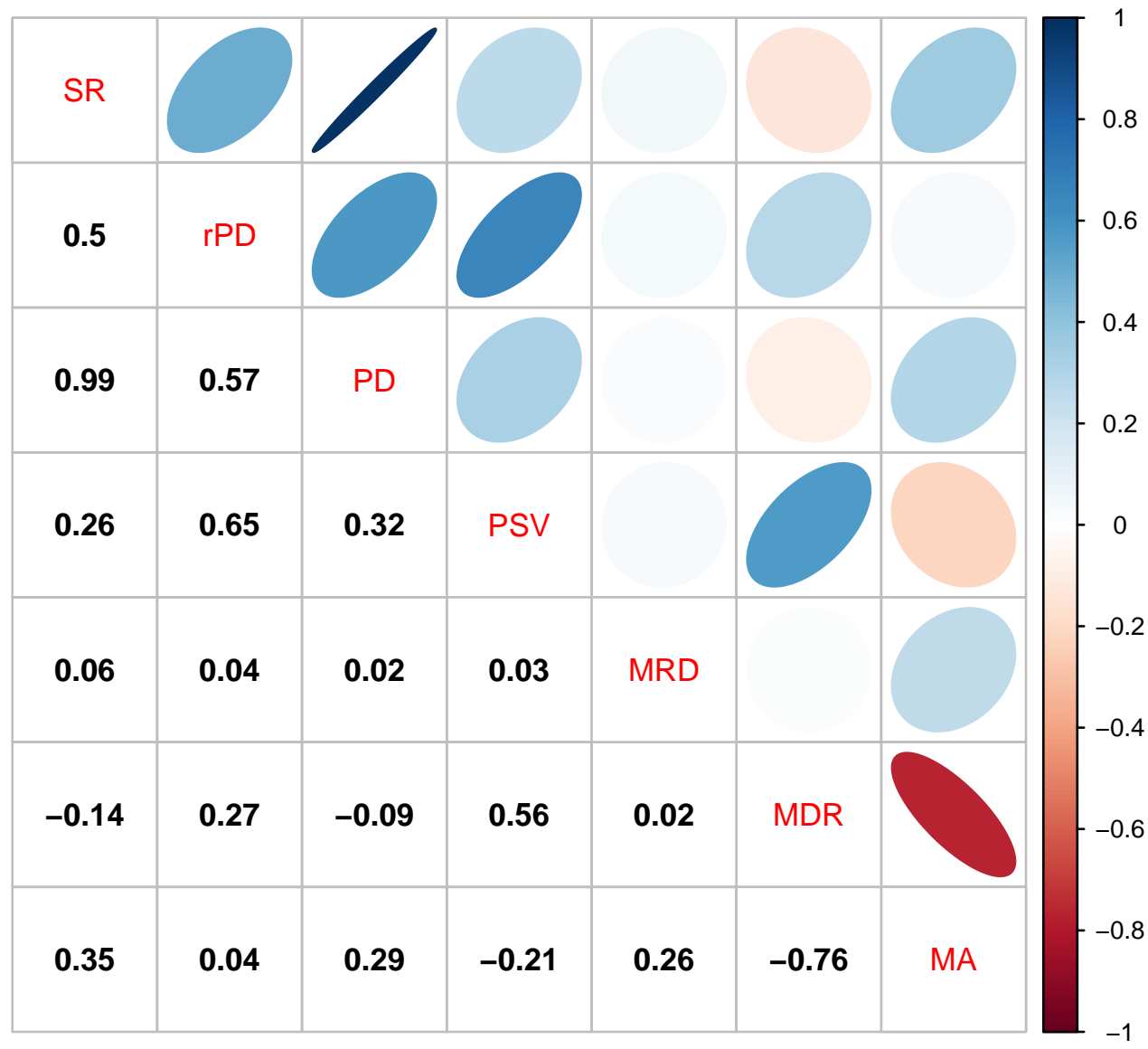

Hylids

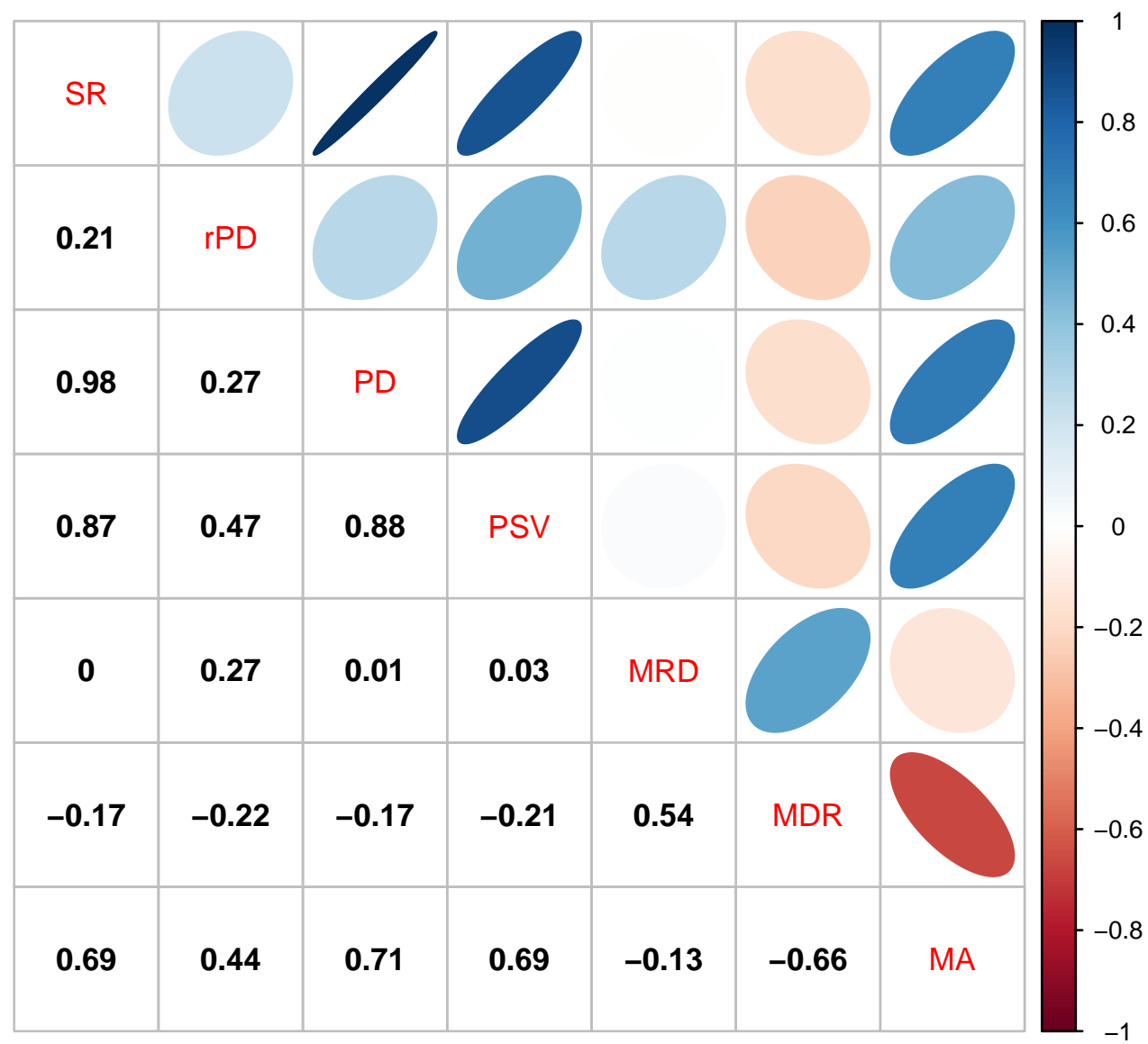

\section{Furnariides}

\begin{tabular}{|c|c|c|c|c|c|c|}
\hline SR & & & & . & 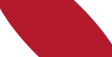 & . \\
\hline 0.14 & rPD & & & & & \\
\hline 0.99 & 0.22 & PD & & & & \\
\hline 0.82 & 0.5 & 0.86 & PSV & & & \\
\hline-0.58 & -0.53 & -0.63 & -0.76 & MRD & & \\
\hline-0.79 & -0.47 & -0.82 & -0.85 & 0.77 & MDR & \\
\hline 0.76 & 0.56 & 0.8 & 0.88 & -0.81 & -0.87 & MA \\
\hline
\end{tabular}



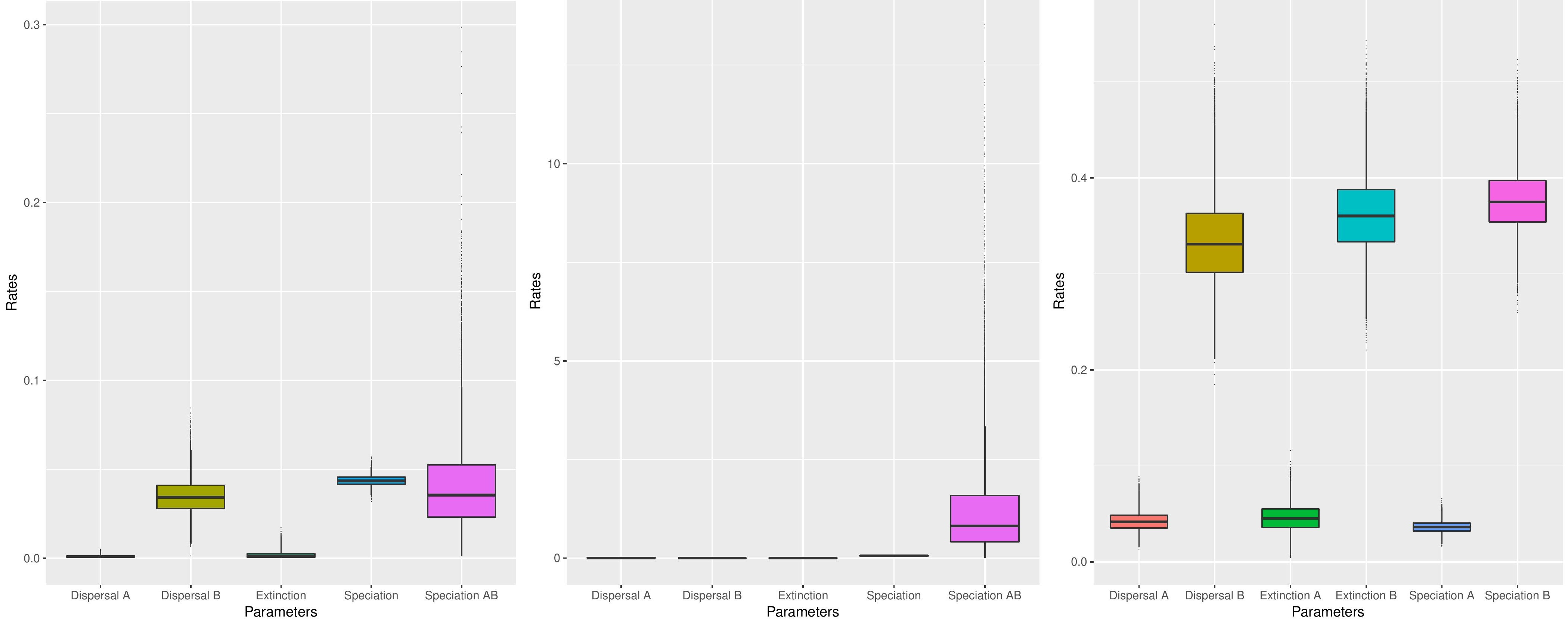







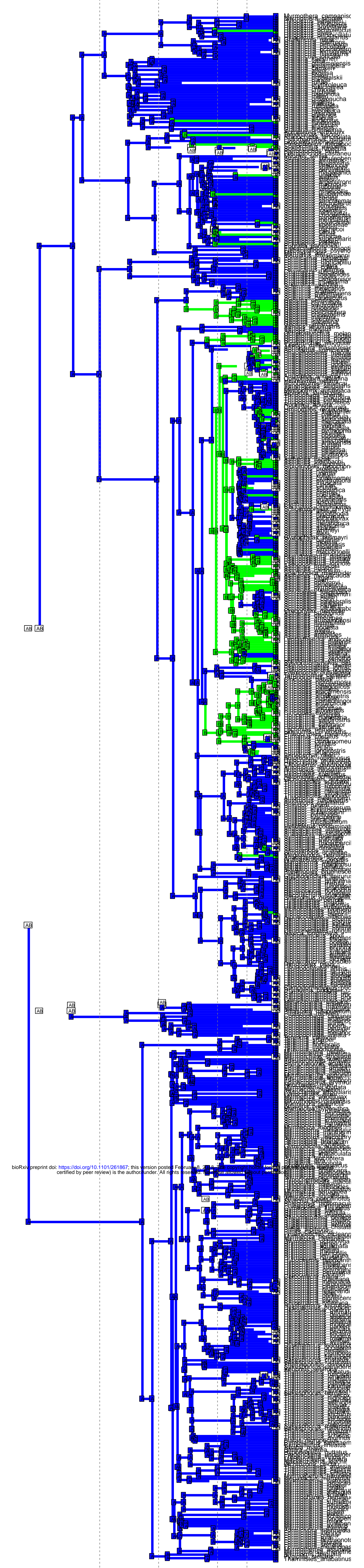




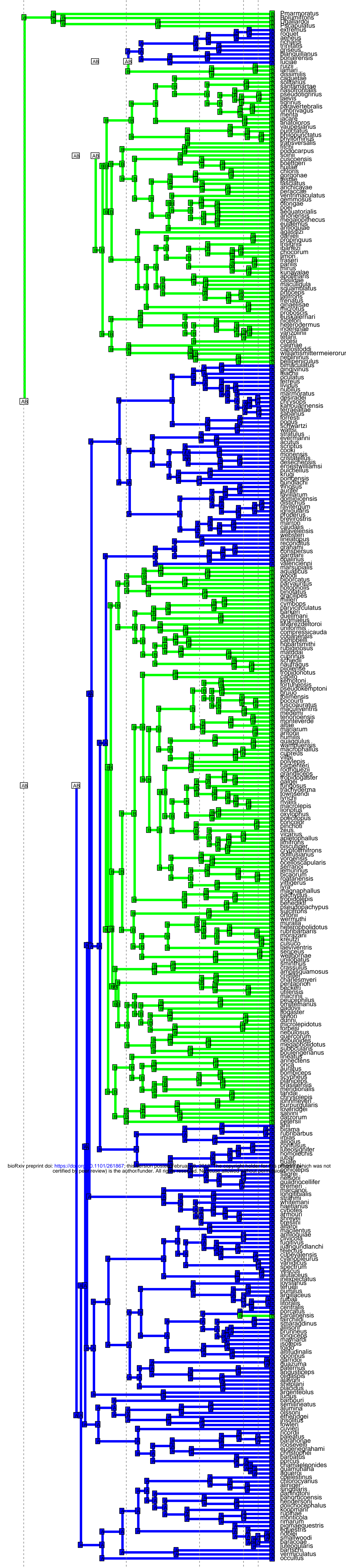

